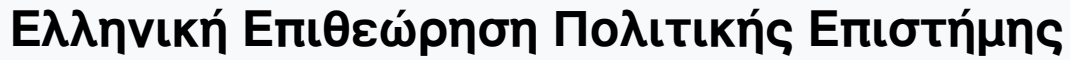

Tó 36 (2010)

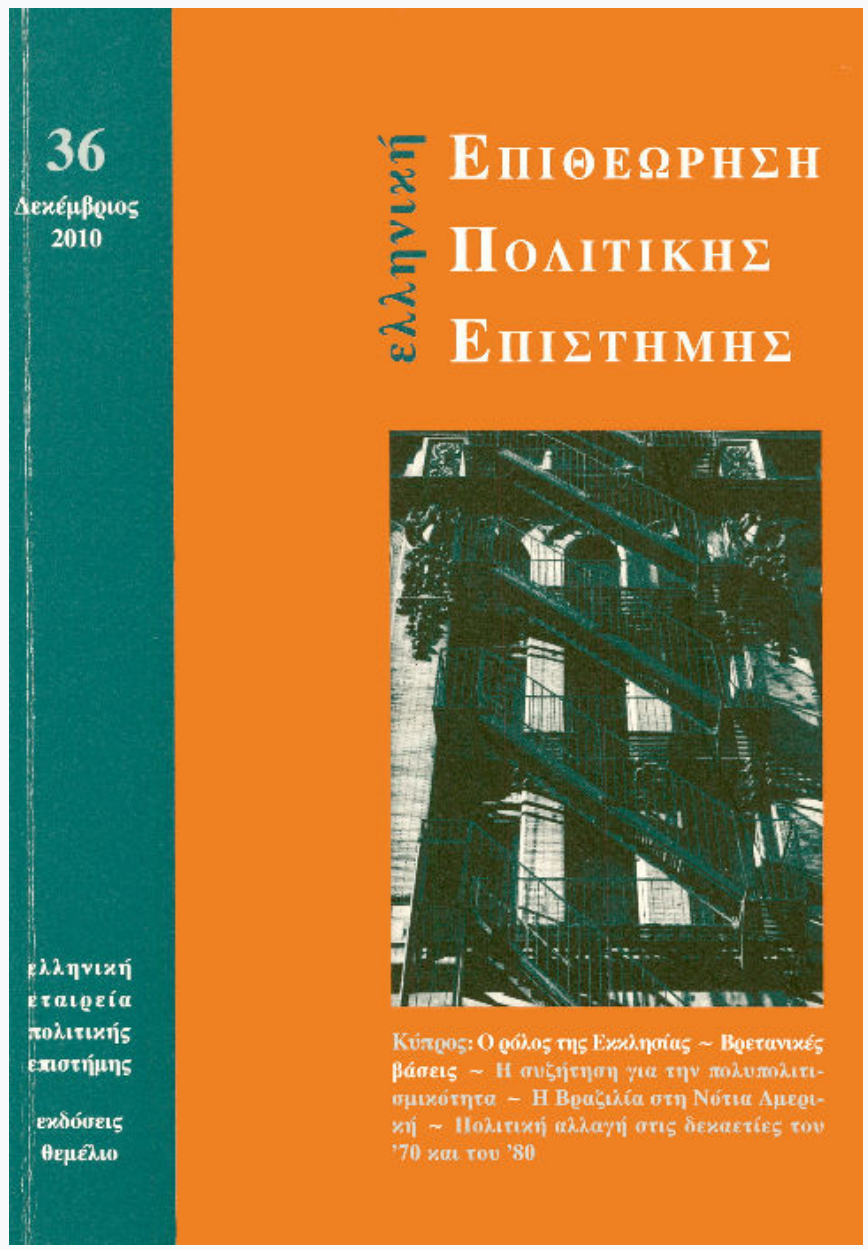

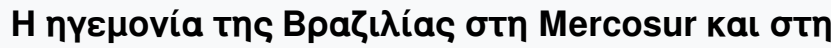

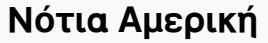

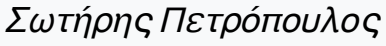

doi: $10.12681 / \mathrm{hpsa} .14508$

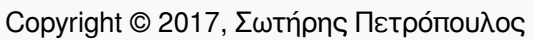

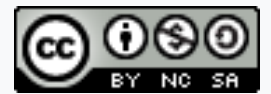

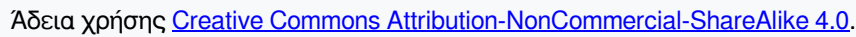

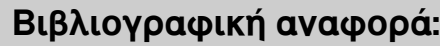

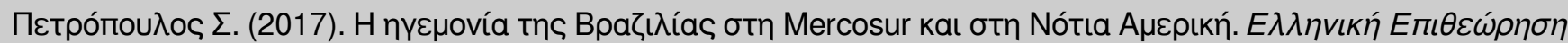

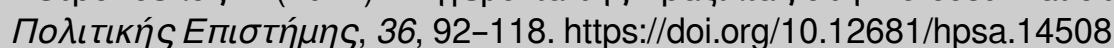




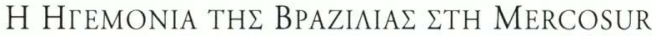 KAI $\Sigma$ TH NOTIA AMEPIKH
}

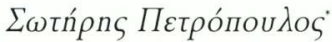

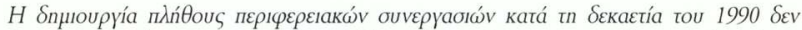

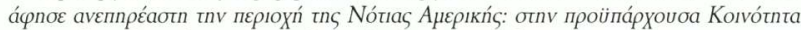

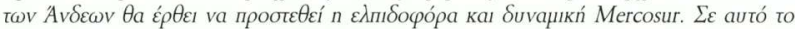

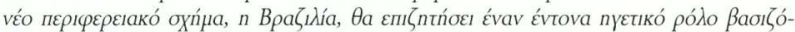

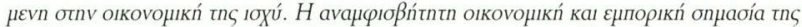

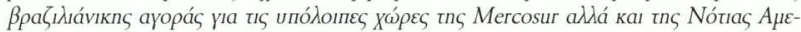

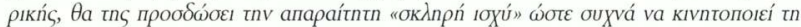

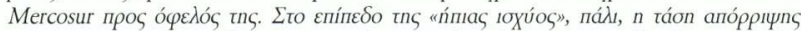

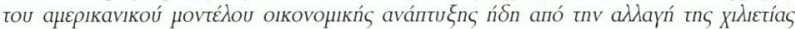

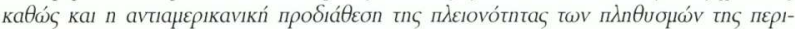

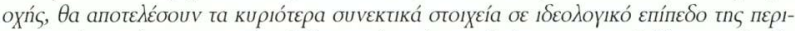

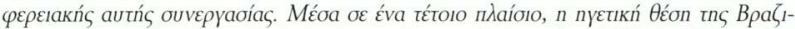

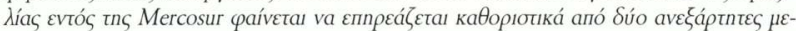

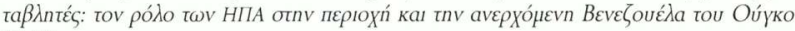
Tó́ßes.

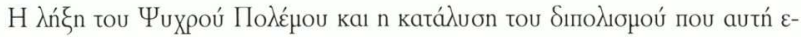

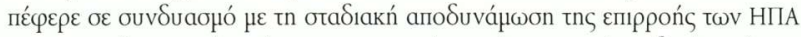

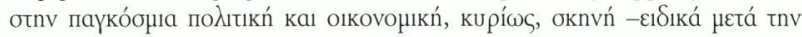

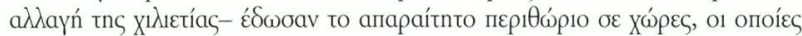

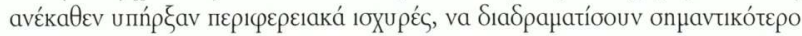

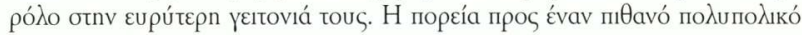

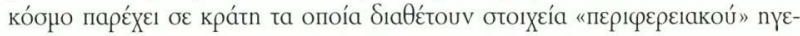

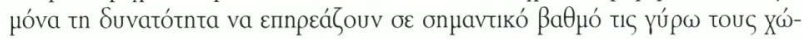

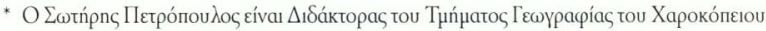

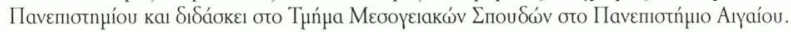




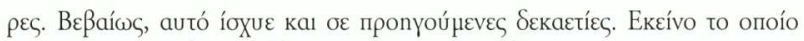

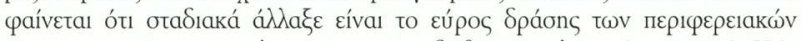

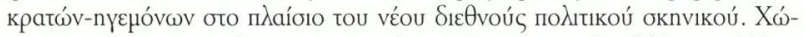

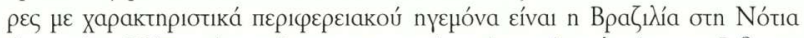

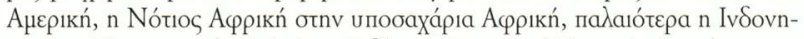

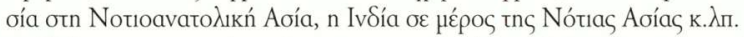

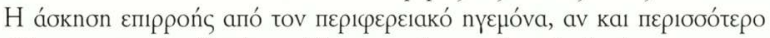

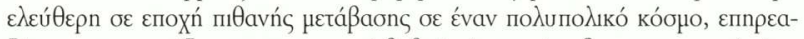

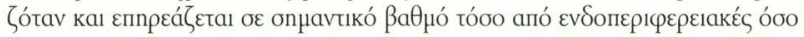

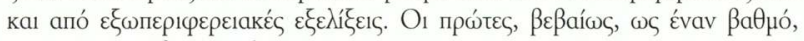

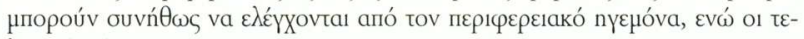

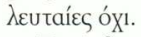

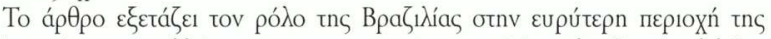

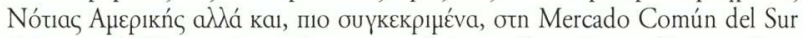

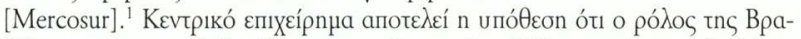

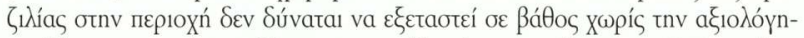

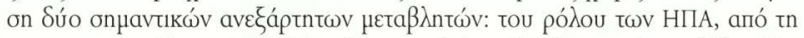

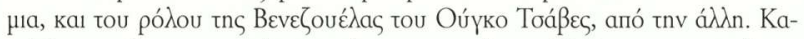

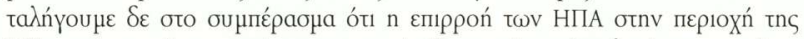

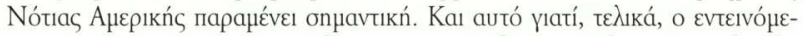

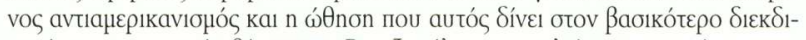

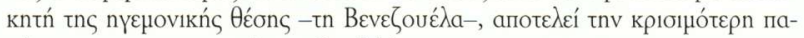

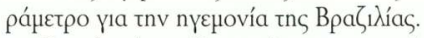

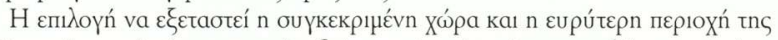

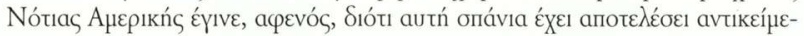

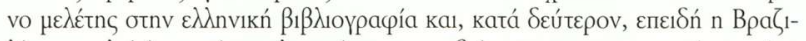

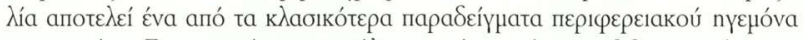

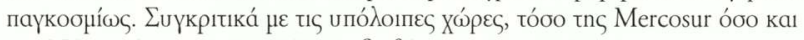

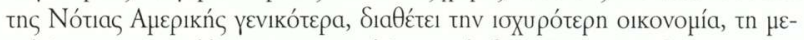

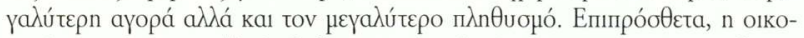

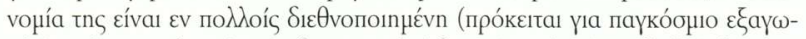

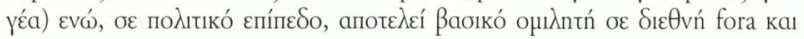

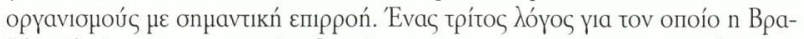

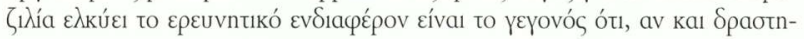

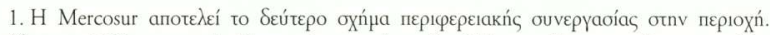

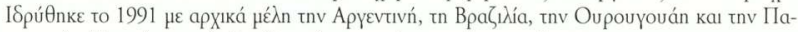

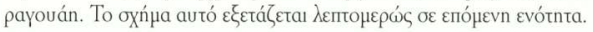




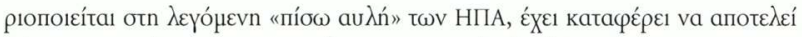

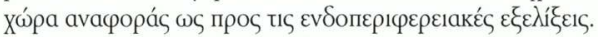

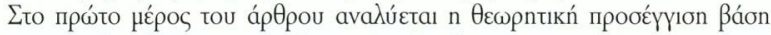

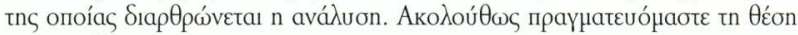

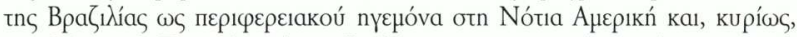

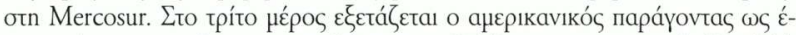

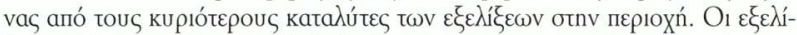

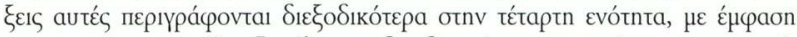

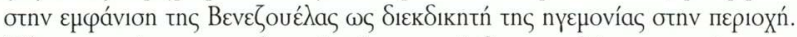

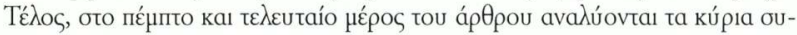

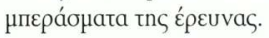

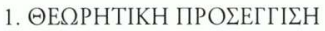

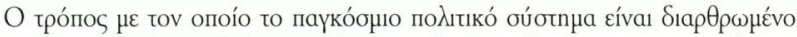

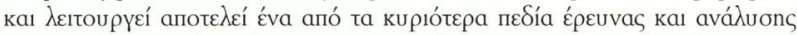

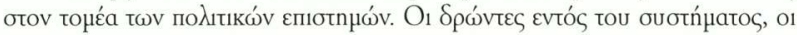

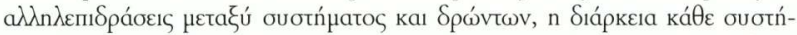

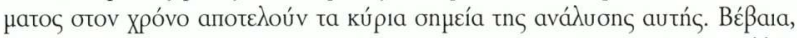

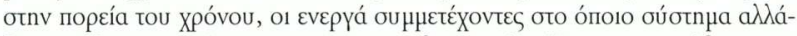

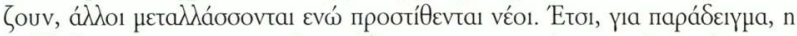

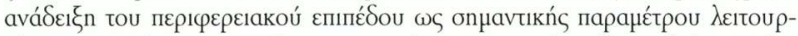

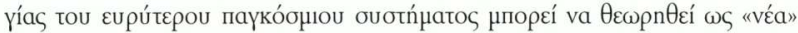

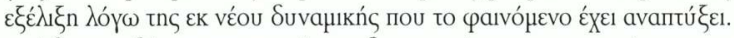

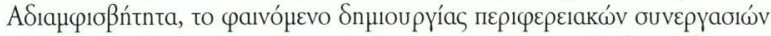

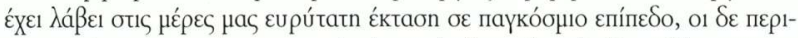

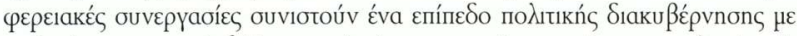

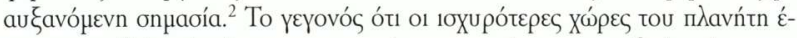

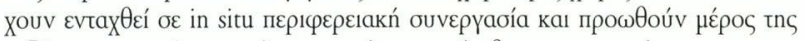

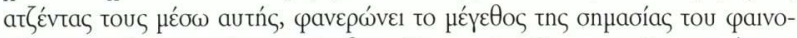

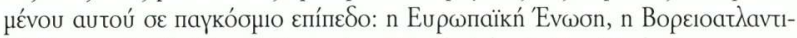

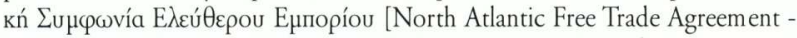

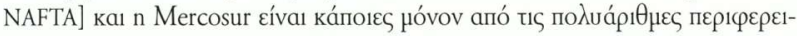

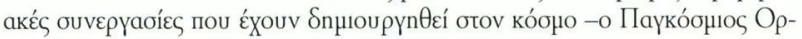

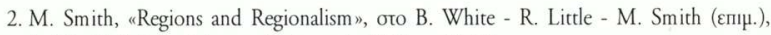
Issues in World Politics, Palgrave, Basingstoke 2001, o. 72-73. 


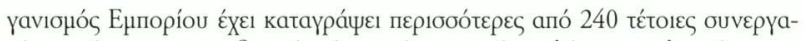

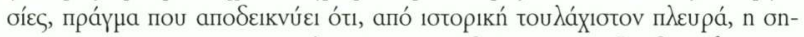

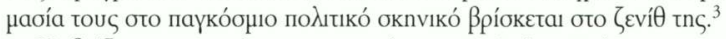

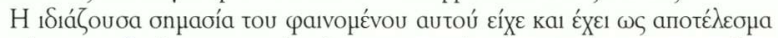

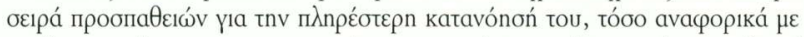

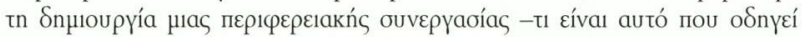

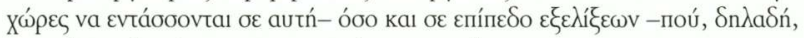

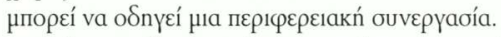

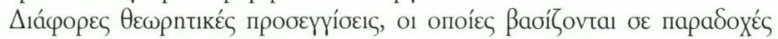

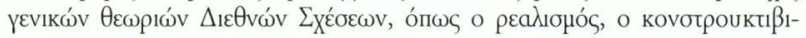

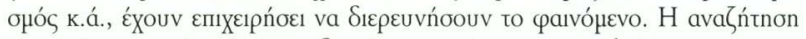

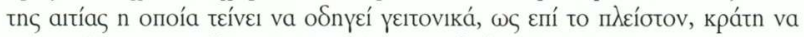

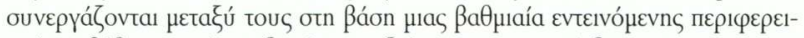

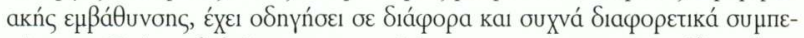

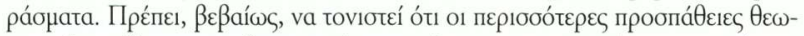

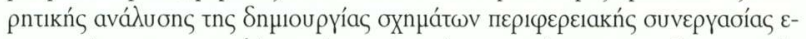

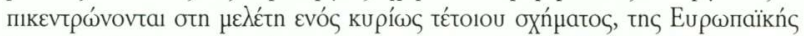

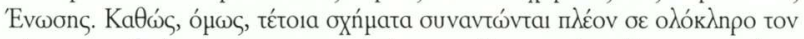

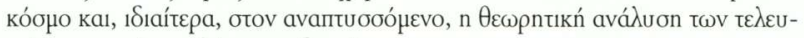

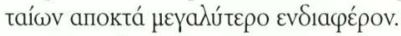

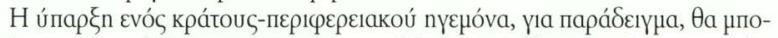

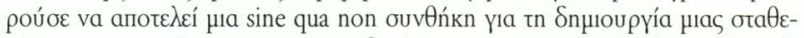

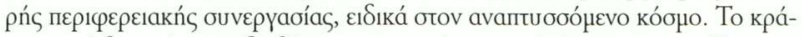

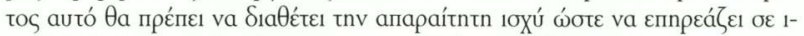

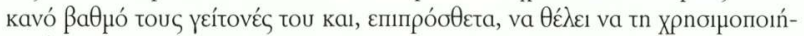

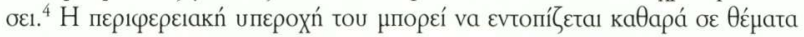

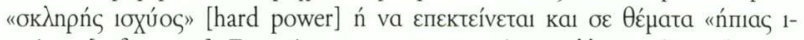

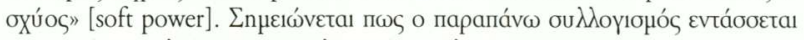

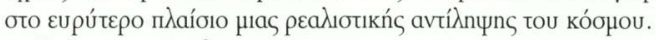

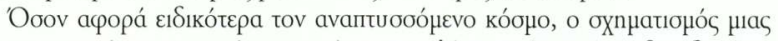

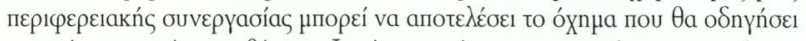

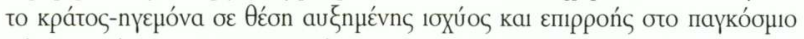

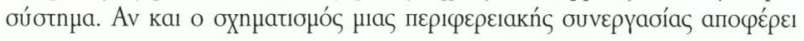

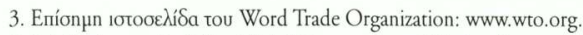

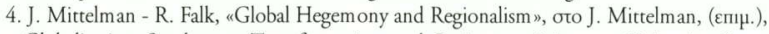
The Globalization Syndrome: Transformation and Resistance, Princeton University Press, Princeton 2000, o. 138-139. 


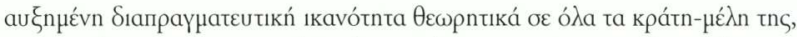

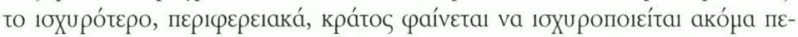

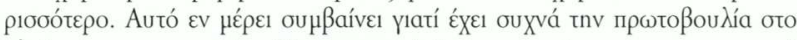

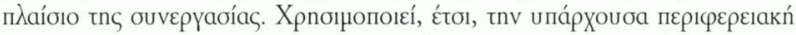

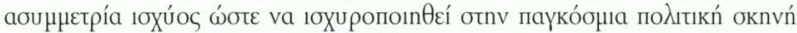

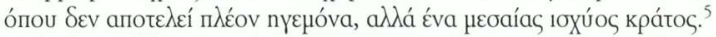

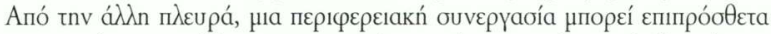

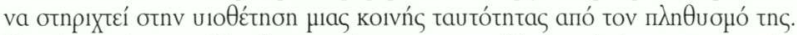

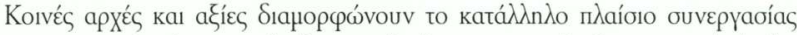

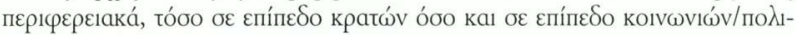

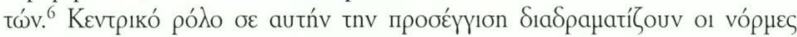

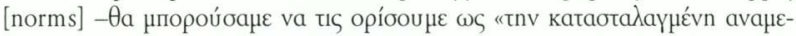

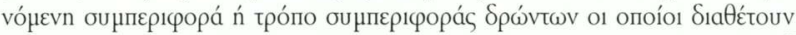

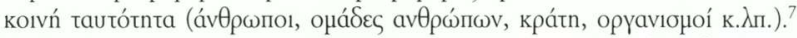

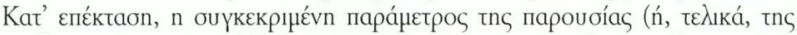

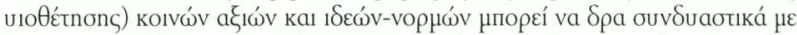

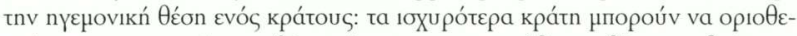

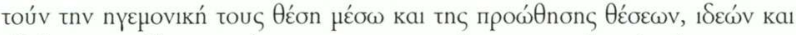

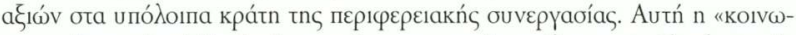

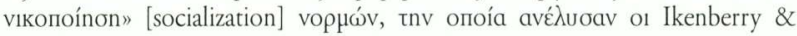

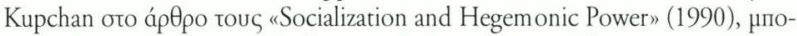

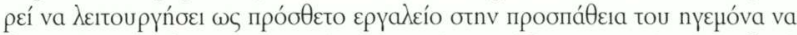

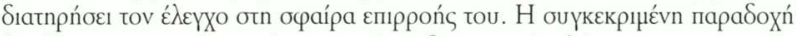

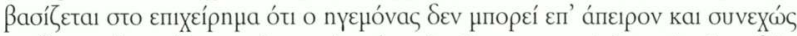

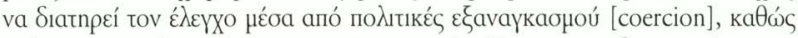

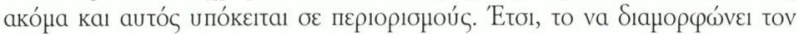

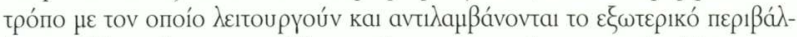

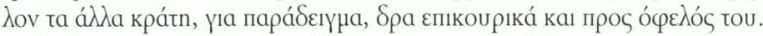

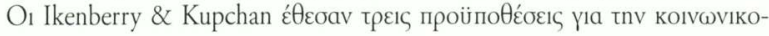

5. D. Crone, «Does Hegemony Matter? The Reorganization of the Pacific Political Economy», World Politics, tón. 45, тx. 4, 1993, о. 504.

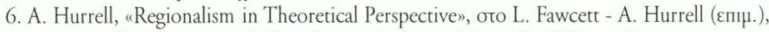

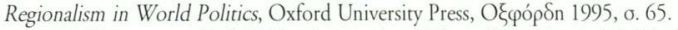

7. M. Finnemore - K. Sikkink, "International Norm Dynamics and Political Change", In-

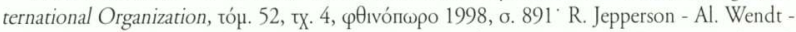

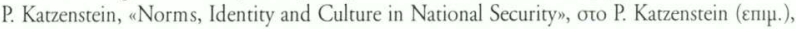
The Culture of National Security, Columbia University Press, Néa Yópkn 1996, б. 54. 


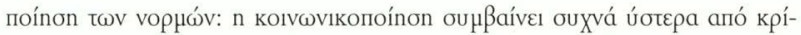

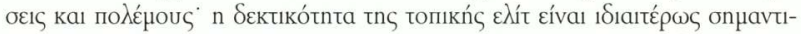

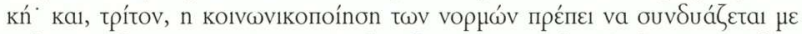
по

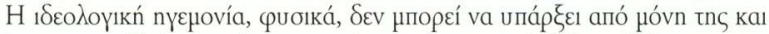

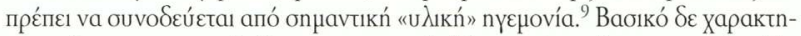

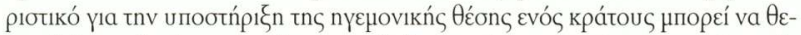

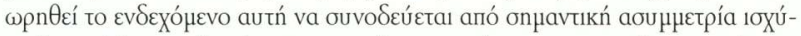

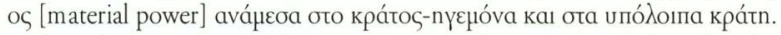

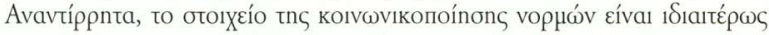

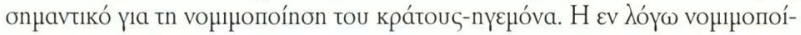

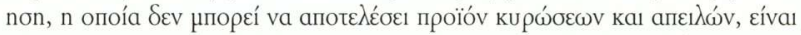

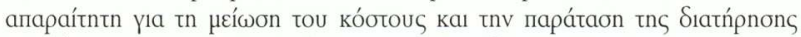

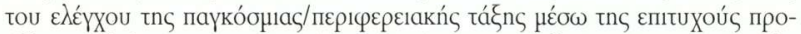

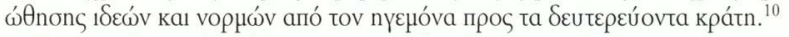

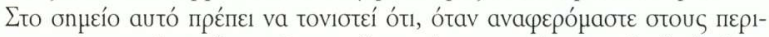

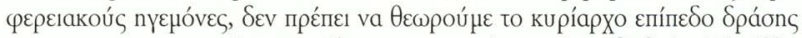

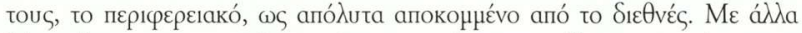

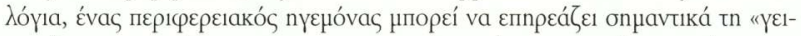

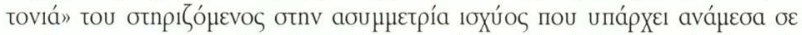

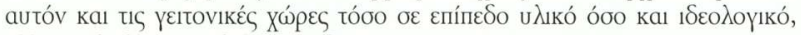

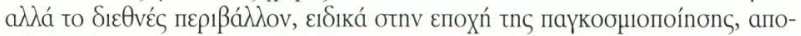

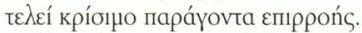

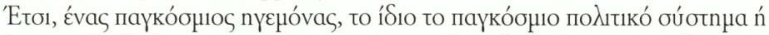

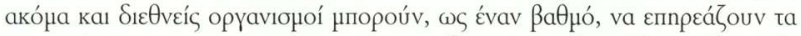

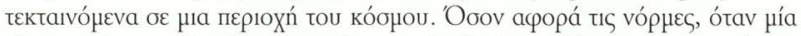

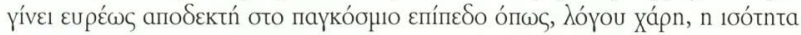

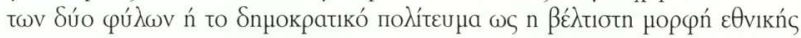

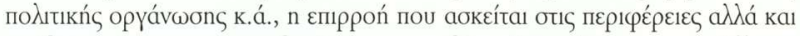

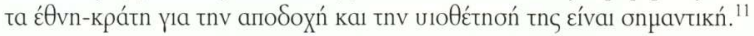

8. J. Ikenberry - Ch. Kupchan, «Socialization and hegemonic power», International Organization, tóp. 44, тx. 3, 1990, б. 283-284.

9. D. Lake, «Leadership, Hegemony, and the International Economy: Naked Emperor or Tattered Monarch with Potential?m, International Studies Quarterly, tó . 37, тx. 4, 1993, o. 469-470.

10. J. Ikenberry - Ch. Kupchan, «Socialization and hegemonic power», ó.m., о. 288-289.

11. M. Finnemore - K. Sikkink, "International Norm Dynamics and Political Change», о́.п., б. 901-902. 


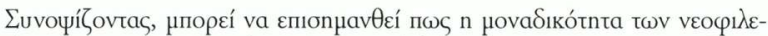

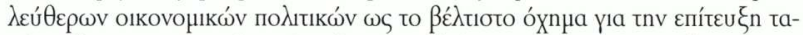

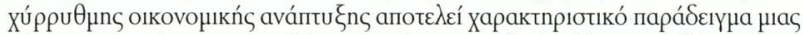

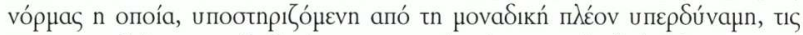

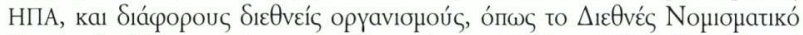

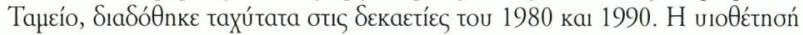

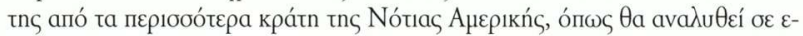

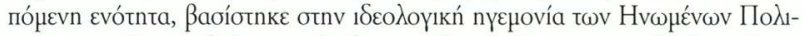

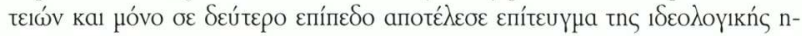

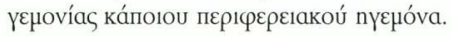

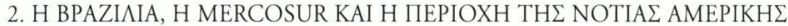

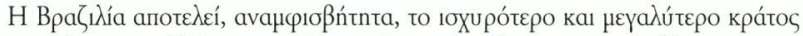

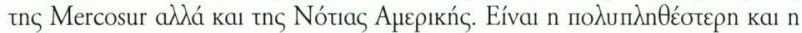

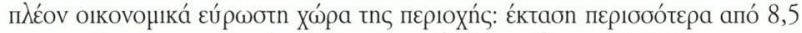

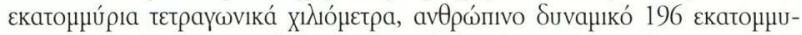

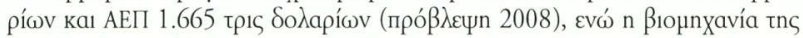

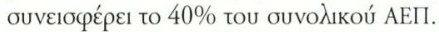

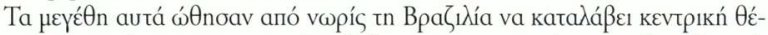

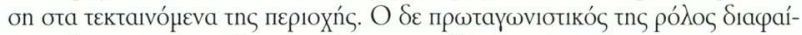

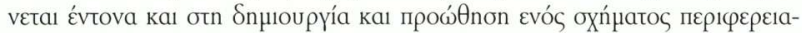

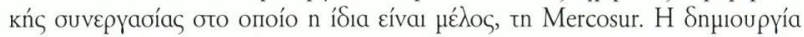

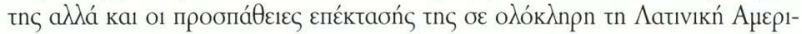

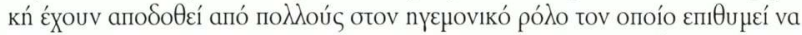

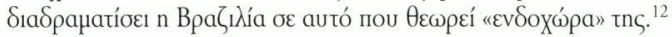

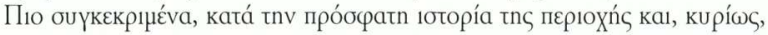

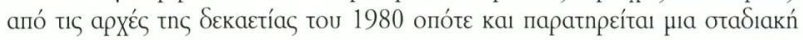

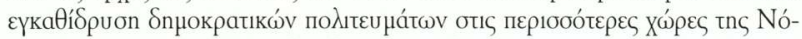

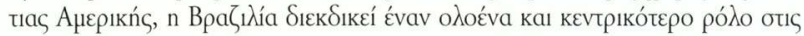

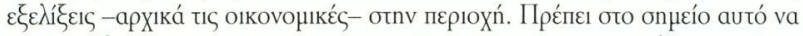

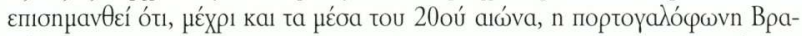

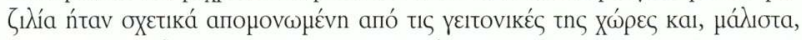

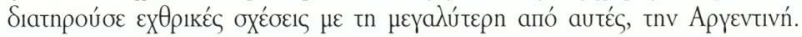

12. A. Malamud, «Mercosur Turns 15: Between Rising Rhetoric and Declining Achievement", Cambridge Review of International Affairs, tóp. 18, тx. 3, 2005, o. 425. 


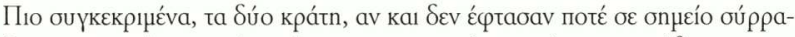

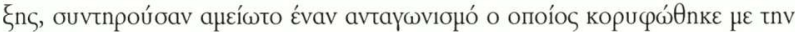

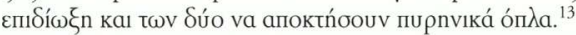

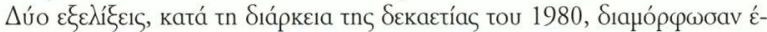

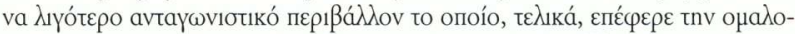

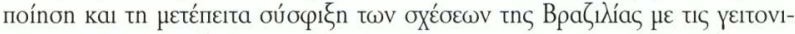

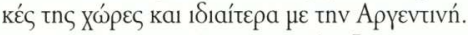

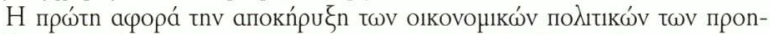

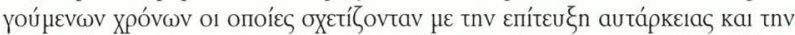

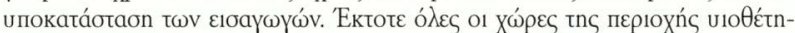

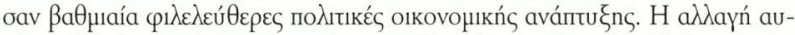

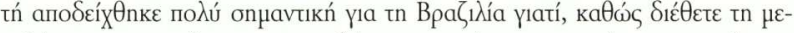

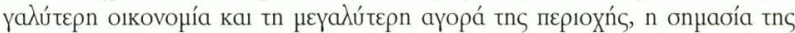

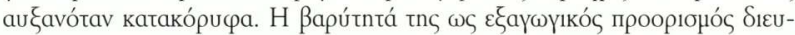

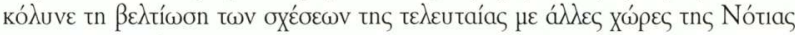

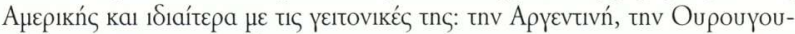
án kal tnv Пlapayouán. ${ }^{14}$

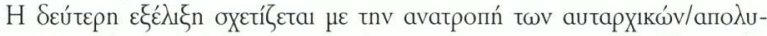

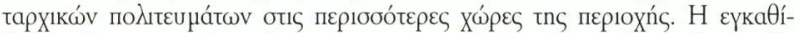

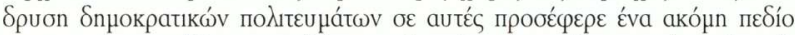

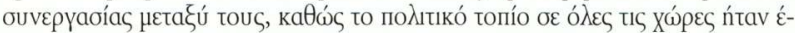

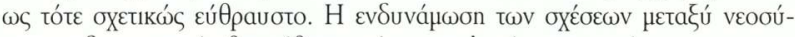

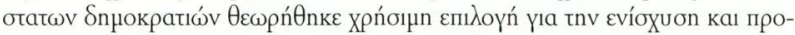

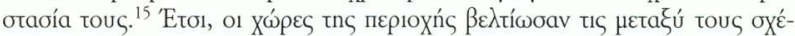

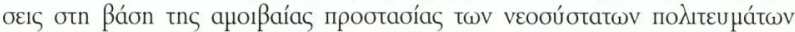

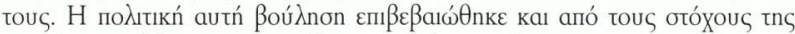

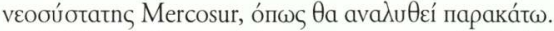

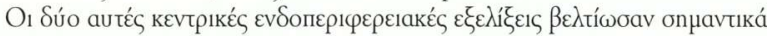

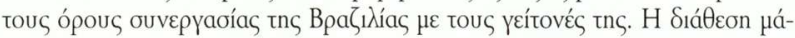

13. P. Cammack, «MERCOSUR: From Domestic Concerns to Regional Influence», бто G.

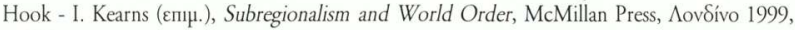
б. 109 .

14. L. Manzetti, "The Political Economy of Mercosur", Journal of Interamerican Studies and World Affairs, tó 1.35 , тX. 4, 1994, o. 109.

15. K. Kaltenthaler - O.F. Mora, «Explaining Latin American economic integration: the case of Mercosur ", Review of International Political Economy, tóp. 9, тX. 1, Máptios 2002, o.

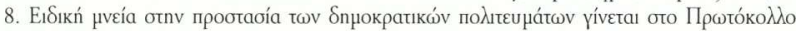
tnc Ushuaia, 1998. 


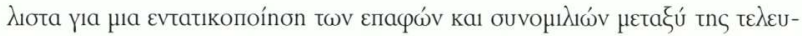

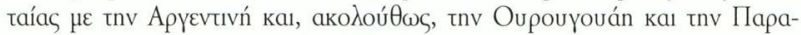

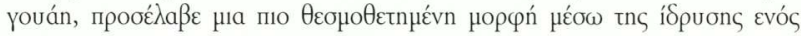
oxń

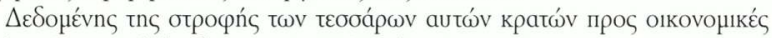

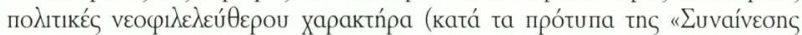

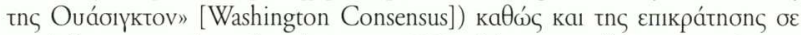

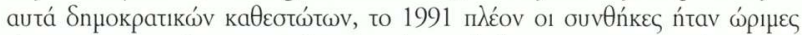

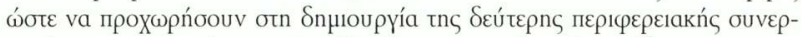

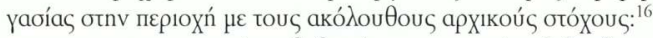

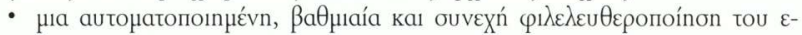

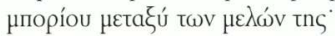

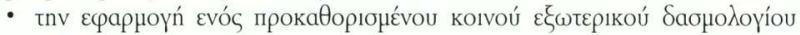
(CERT) $)^{\circ}$

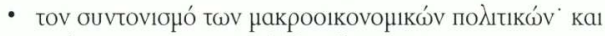

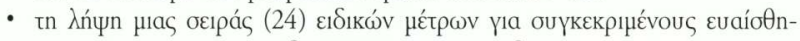

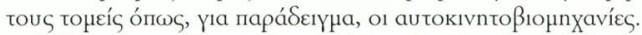

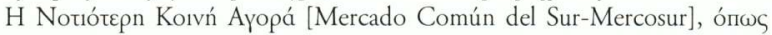

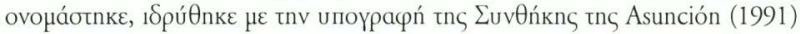

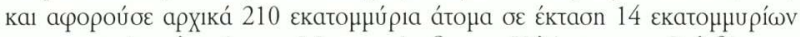

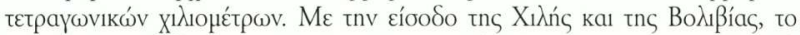

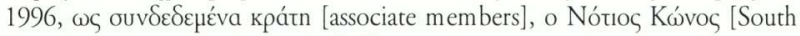

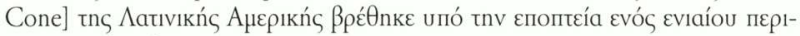
фервıакоú oхńнатоs.

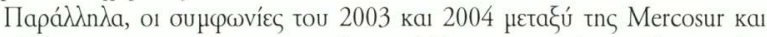

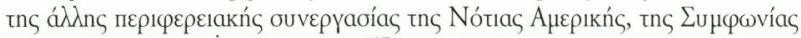

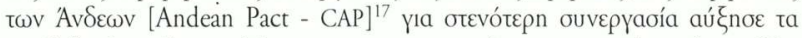

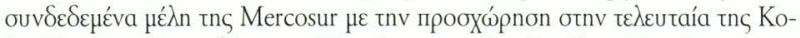

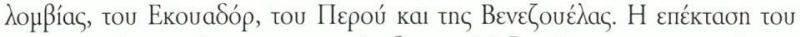

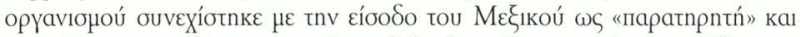

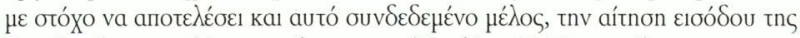

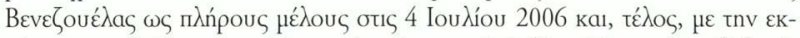

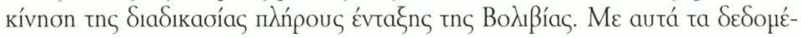

16. ¿uvӨńkn tnç Asunción, 1991.

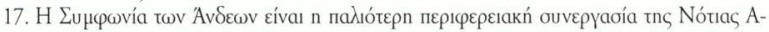

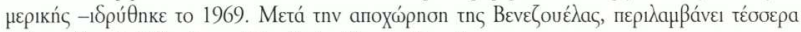

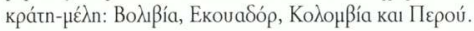




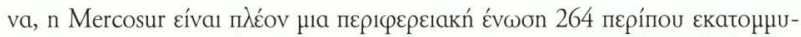

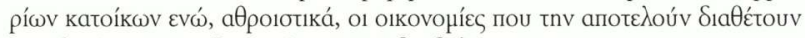

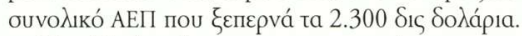

Пара́ $\lambda \lambda$ na, ó

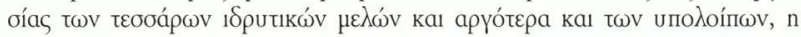

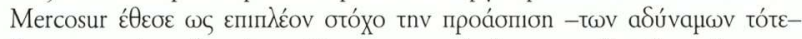

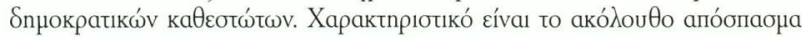

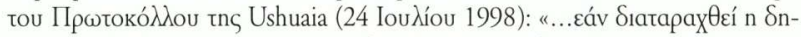

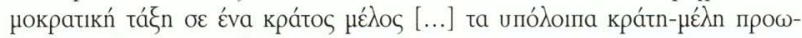

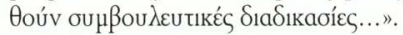

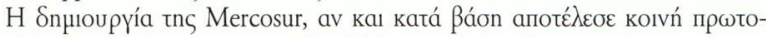

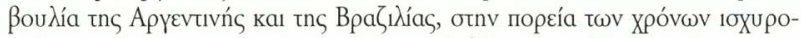

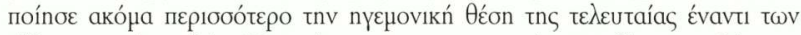

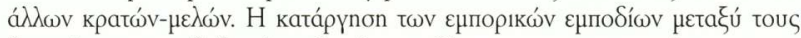

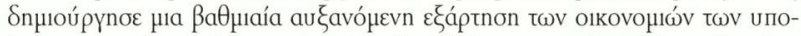

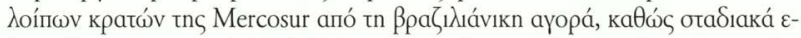

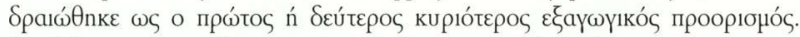

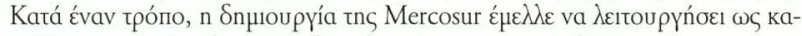

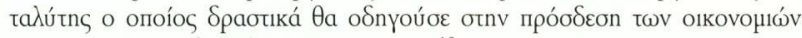

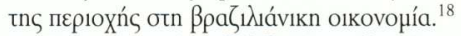

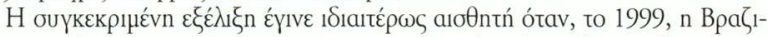

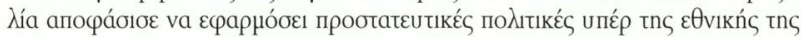

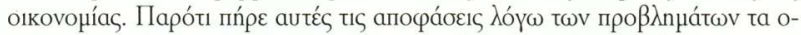

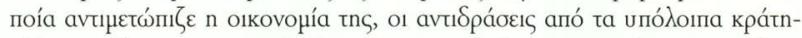

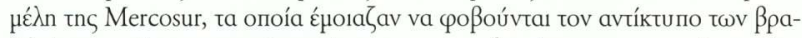

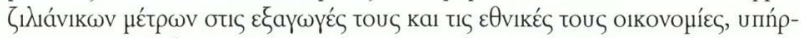

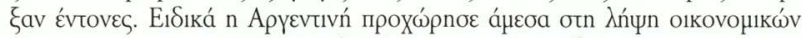

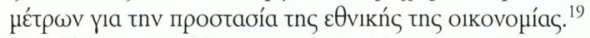

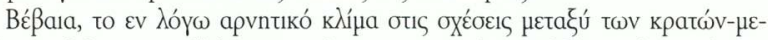

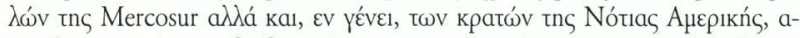

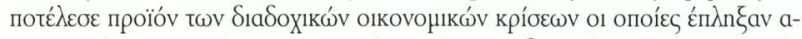

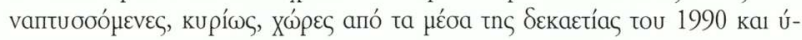

18. A. Bevilaqua - M. Catena - E. Talvi, «Integration, Interdependence and Regional Goods: An Application to Mercosur", Economia, tóp. 2, тx. 1, 2001, o. 160.

19. A. Malamud, "Presidentialism and Mercosur: A Hidden Cause for a Successful Experiencen, ото F. Laursen (впц.), Comparative Regional Integration, Theoretical Perspectives, Ashgate, Surrey 2003, o. 68. 


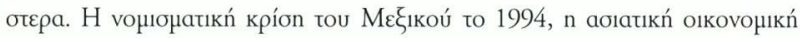

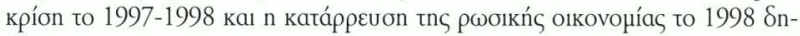

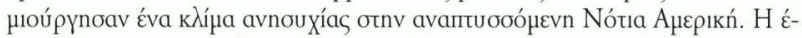

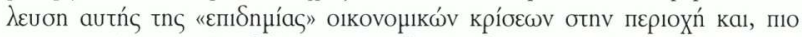

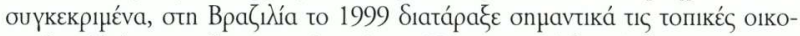

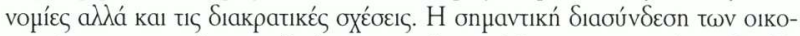

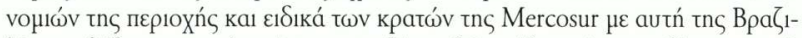

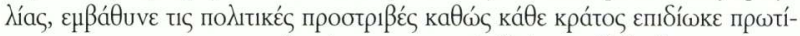

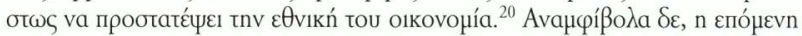

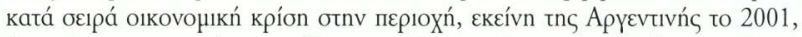

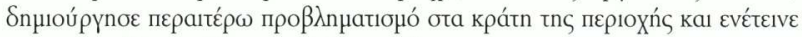

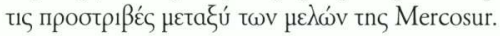

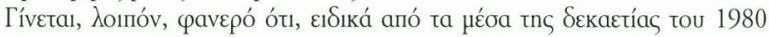

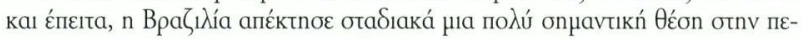

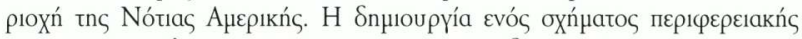

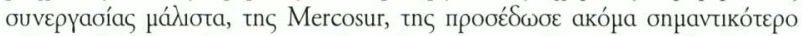

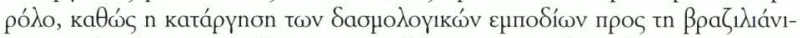

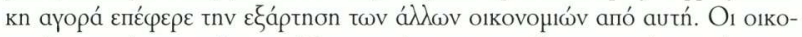

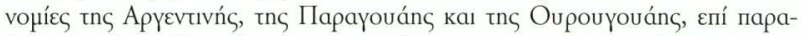

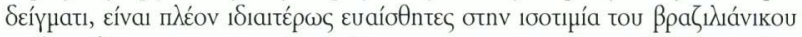

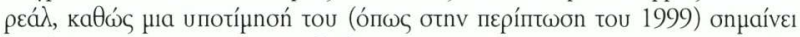

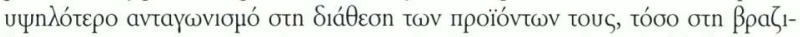

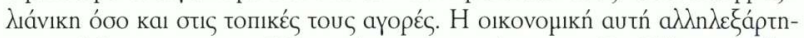

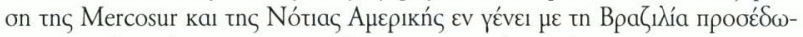

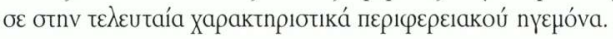

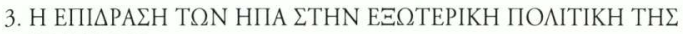 BPAZIAIAE}

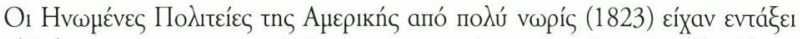

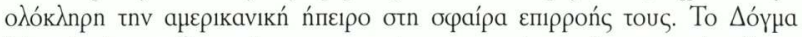

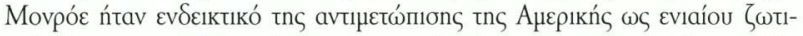
koú X⿳亠丷厂

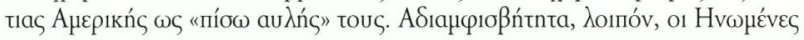

20. A. Bevilaqua - M. Catena - E. Talvi, «Integration, Interdependence and Regional Goods: An Application to Mercosurn, ó.п., б. 160. 


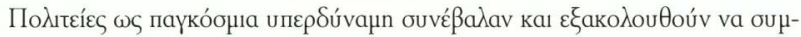

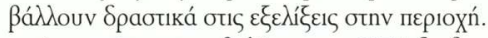

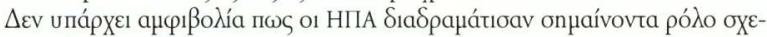

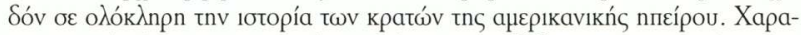

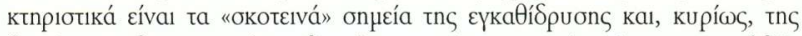

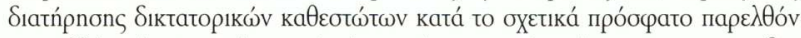

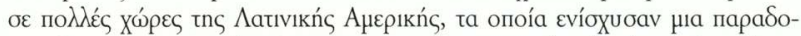

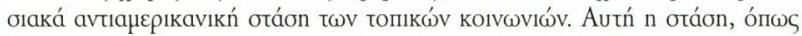

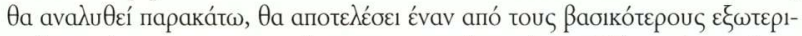

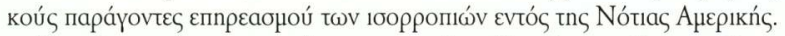

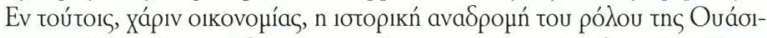

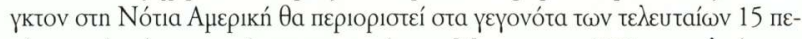

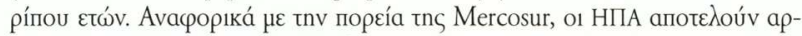

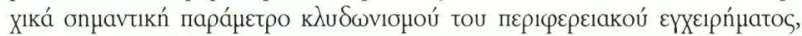

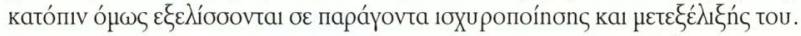

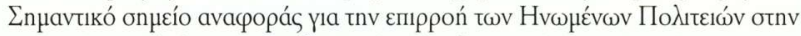

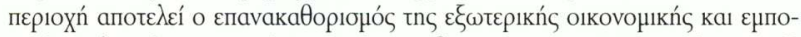

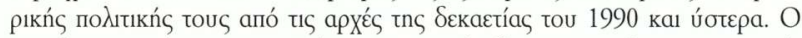

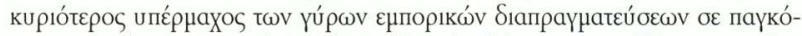

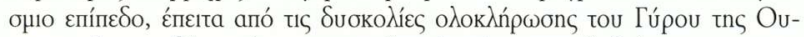

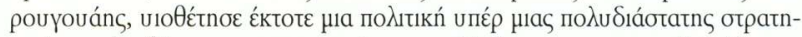
үıкń

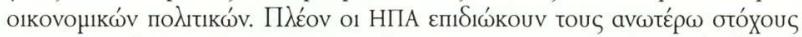

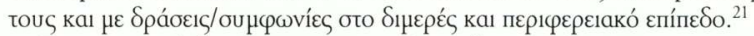

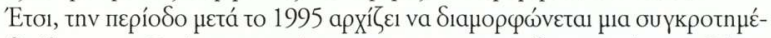

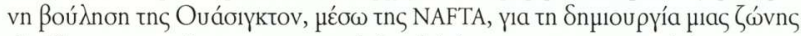

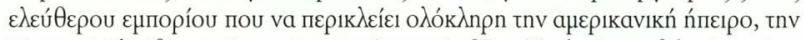

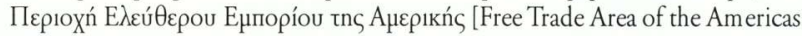

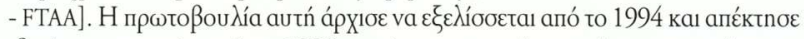

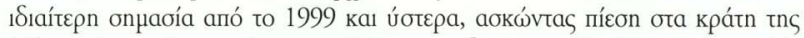

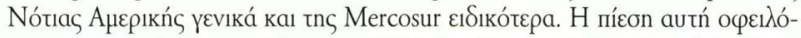

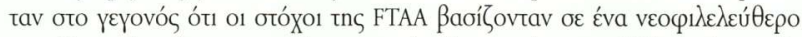

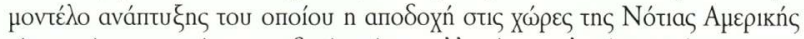

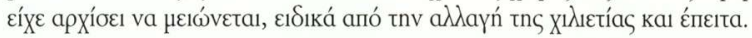

21. S. Breslin - R. Higgott, «Studying Regions: Learning from the old, Constructing the new», New Political Economy, tóp. 5, тx. 3, 2000, ๙. 337-339. 


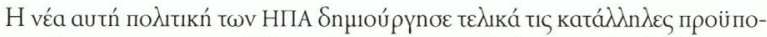

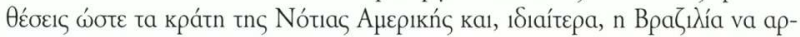

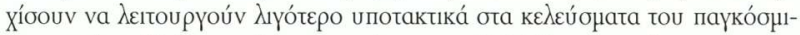

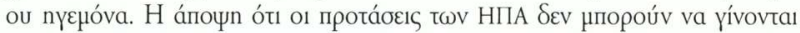

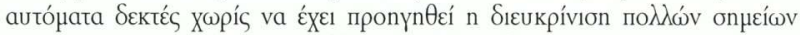

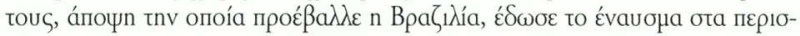

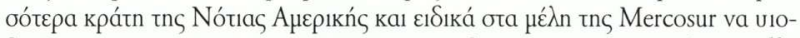

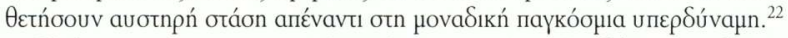

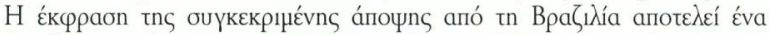

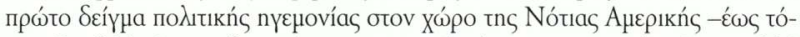

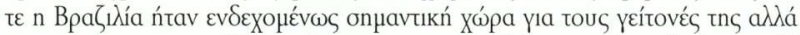

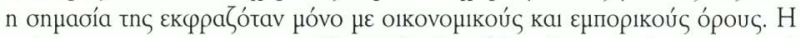

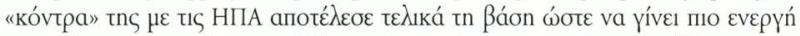

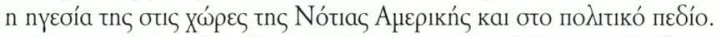

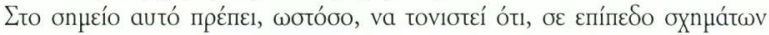

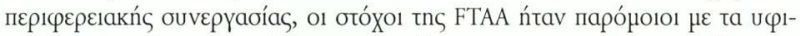

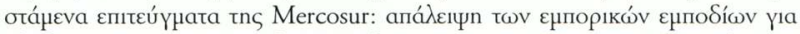

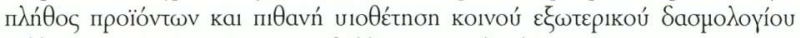

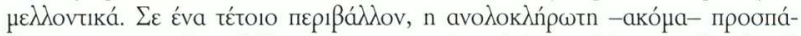

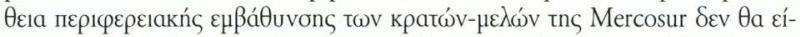

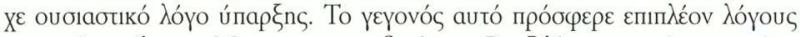

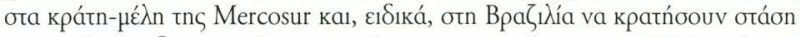

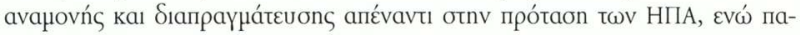

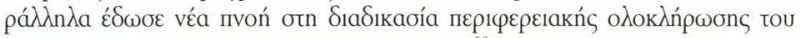

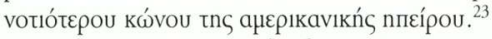

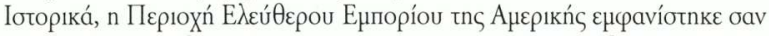

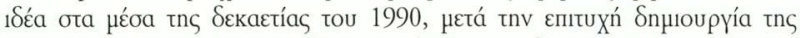

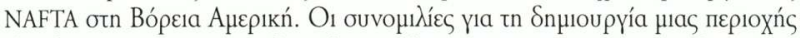

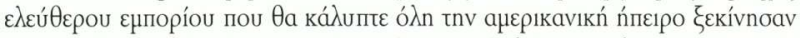

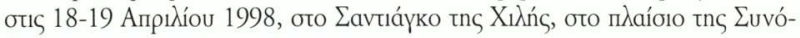

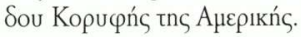

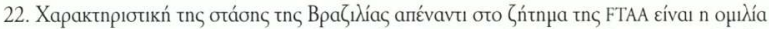

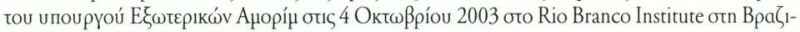

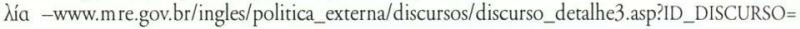
2281.

23. L. Mera, "Explaining Mercosur's Survival: Strategic Sources of Argentine-Brazilian Convergence», Journal of Latin American Studies, tóu. 37, 2005, o. 129-130. 


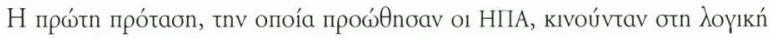

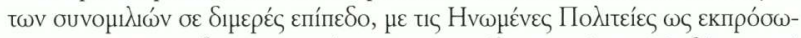

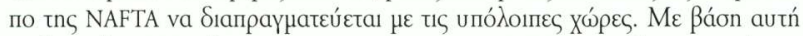

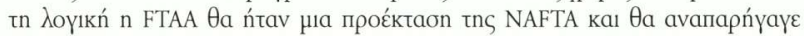

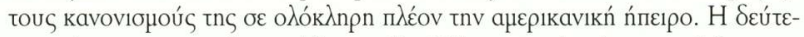

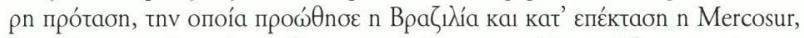

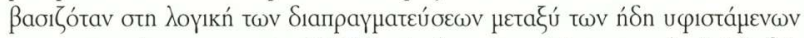

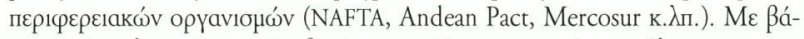

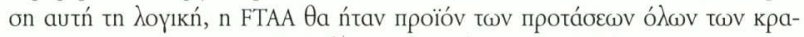

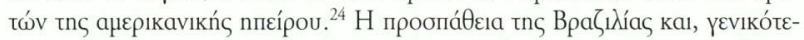

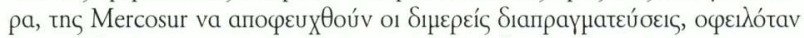

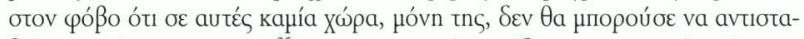

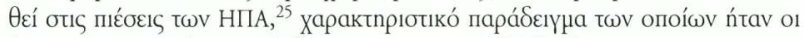

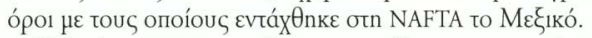

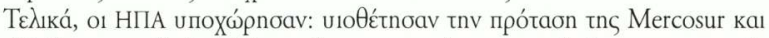

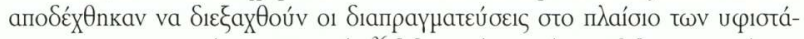

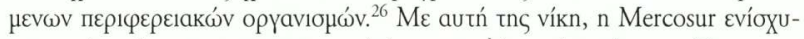

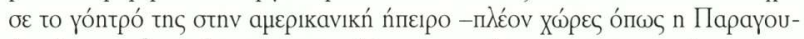

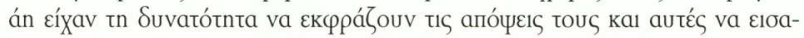

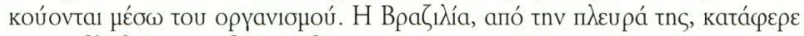

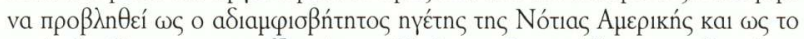

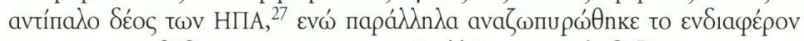

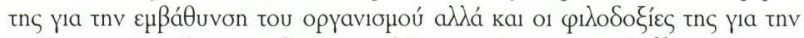

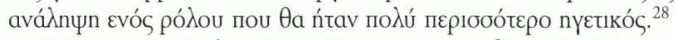

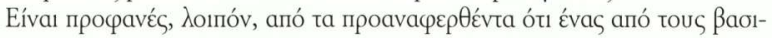

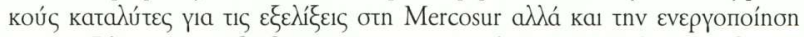

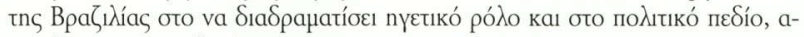

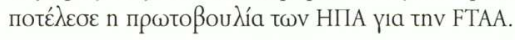

24. M.E. Carranza, "Mercosur and the end game of the FTAA negotiations: challenges and prospects after the Argentine crisis», Third World Quarterly, tóp. 25, тX. 2, 2004, б. 321.

25. N. Philips, "Hemispheric integration and subregionalism in the Americas", International Affairs, tóp. 79, тX. 2, 2003, б. 341.

26. M.E. Carranza, "Mercosur and the end game of the FTAA negotiations: challenges and prospects after the Argentine crisis», ó.п., б. 321-323.

27. Eto í́io, 0. 322.

28. S. Burges, "Without Sticks or Carrots: Brazilian Leadership in South America During the Cardoso Era, 1992-2003", Bulletin of Latin American Research, tó1. 25, тX. 1, 2006, б. 28-29. 


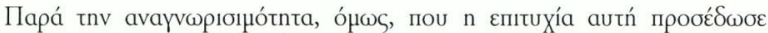

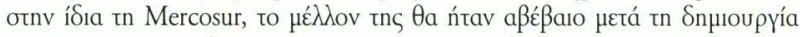

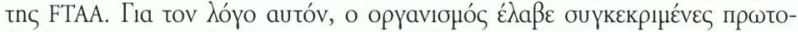

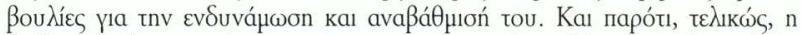

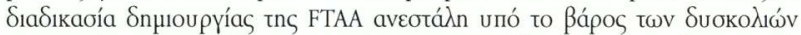

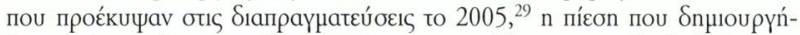

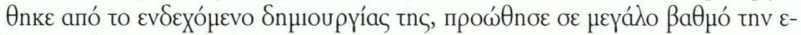

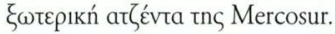

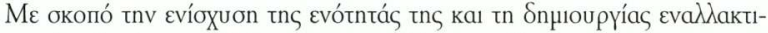

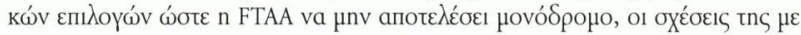

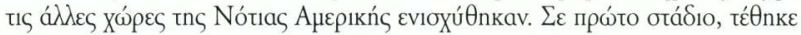

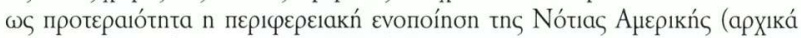
$\mu \varepsilon$ tnv прótaơn $\delta$ nнou pyías tns South American Free Trade Area - SAFTA ка,, anó tov Máı tou 2008, tnç Unión de Naciones Suramericanas - UNASUR),

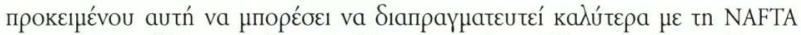

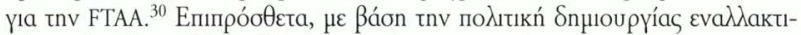

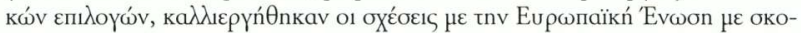

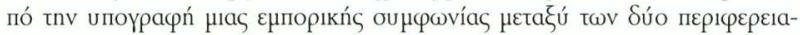

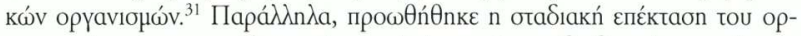

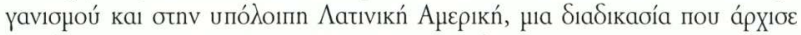

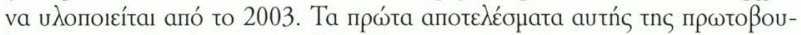

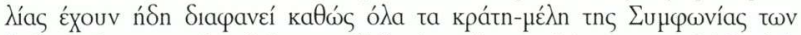

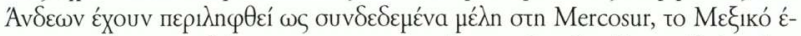

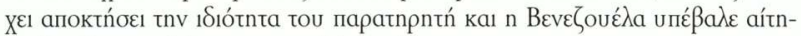

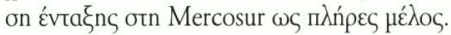

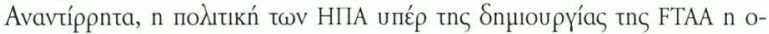

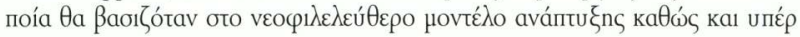

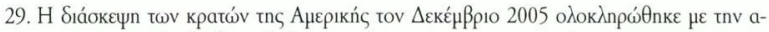

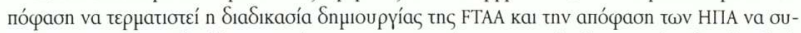

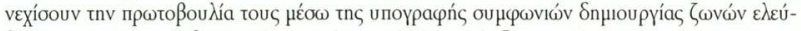

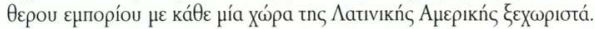

30. N. Phillips, "Governance after financial crisis", oro S. Breslin - Ch.W. Hughes - N. Phillips - B. Rosamond (впц.), New Regionalism in the Global Political Economy: Theories

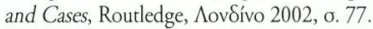

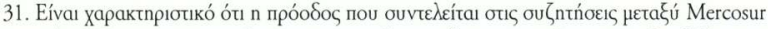

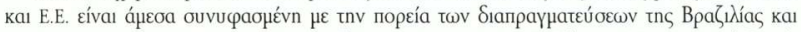

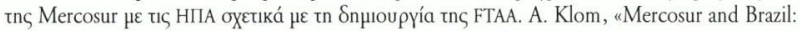
a European perspective», International Affairs, tóu. 79, тx. 2, 2003, б. 356. 


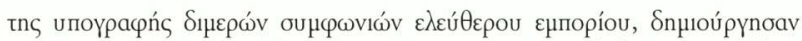

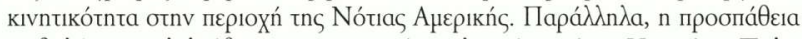

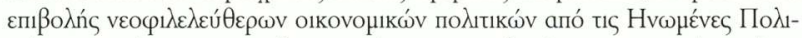

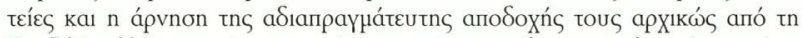

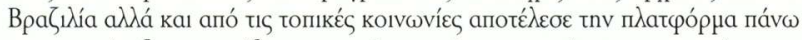

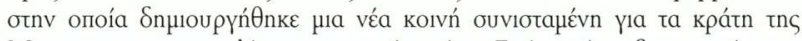

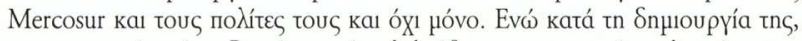

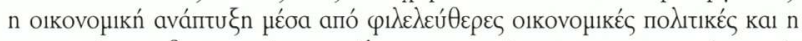

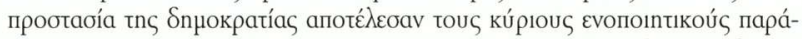

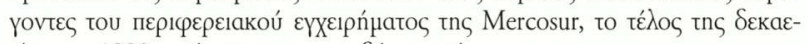

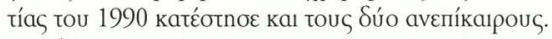

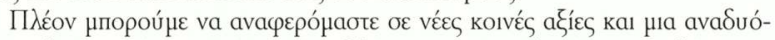

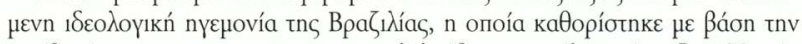

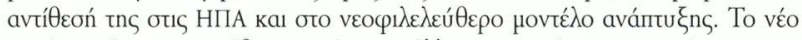

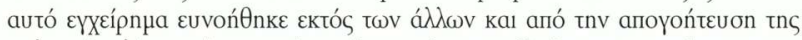

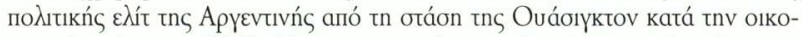

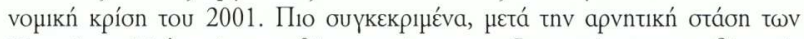

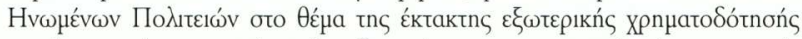

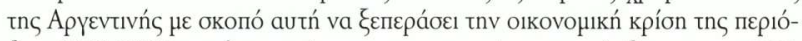

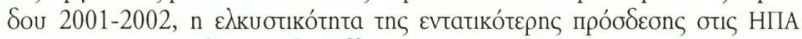

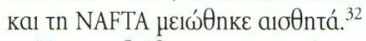

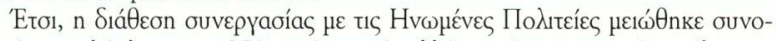

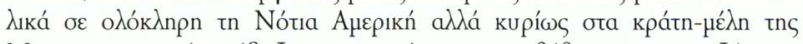

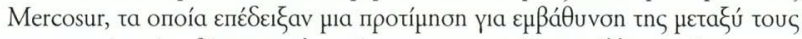

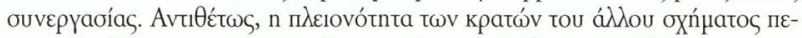

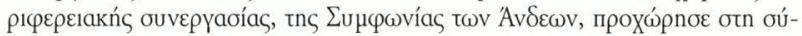

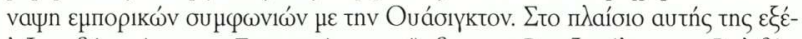

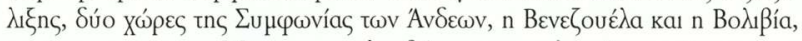

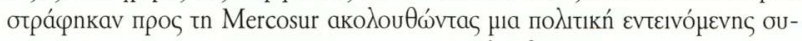

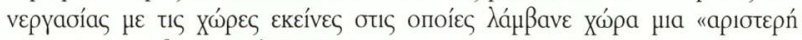

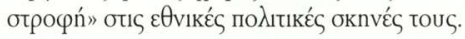

32. M.E. Carranza, «Mercosur and the end game of the FTAA negotiations: challenges and prospects after the Argentine crisis», о́.п., б. 326. 


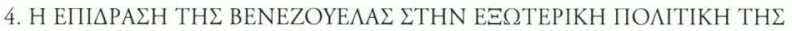
BPAZIAIAL

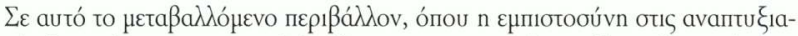

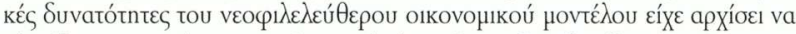

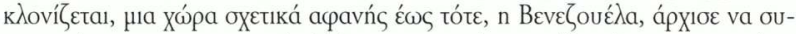

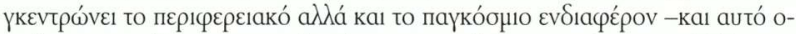

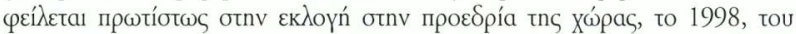

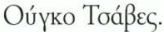

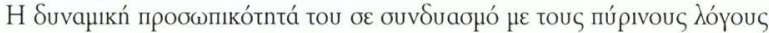

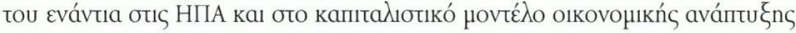

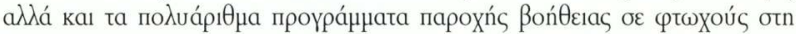

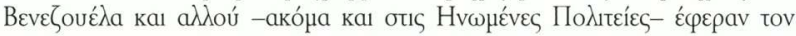

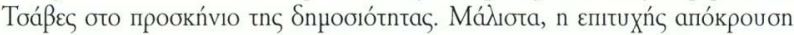

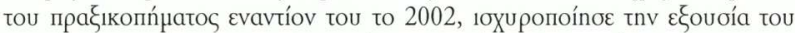

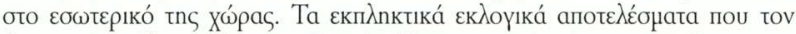

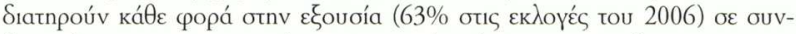

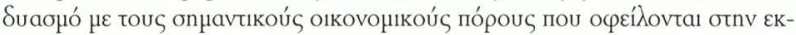

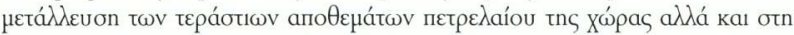

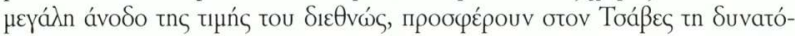

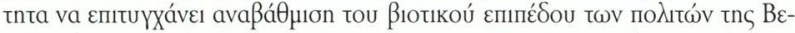

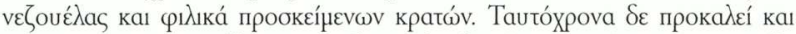

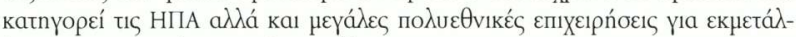

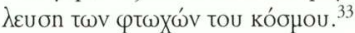

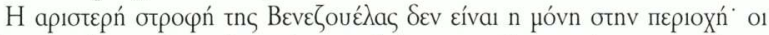

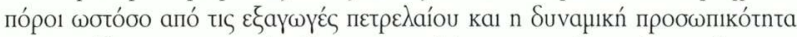

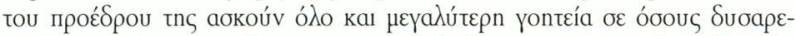

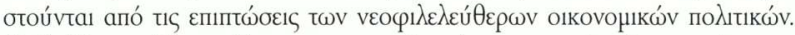

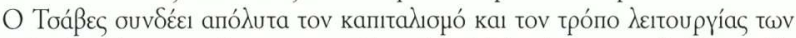

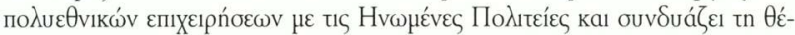

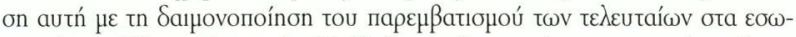

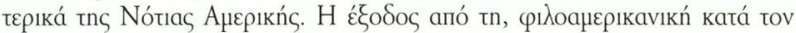

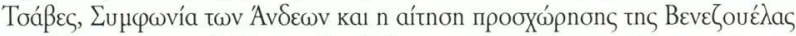

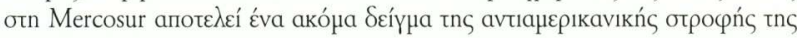

33. S. Christensen, «The influence of nationalism in Mercosur and in South America-can the regional integration project survive?», Revista Brasiliera de Politica Internacional, tóp. 50, тx. 1, 2007, б. 142. 


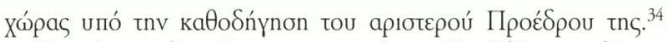

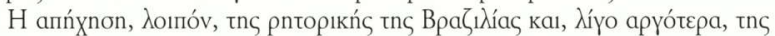

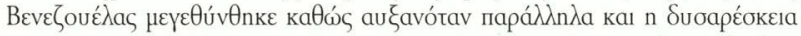

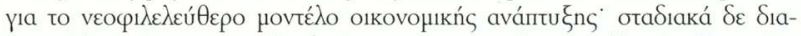

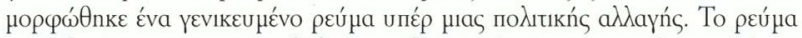

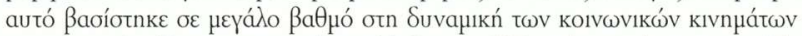

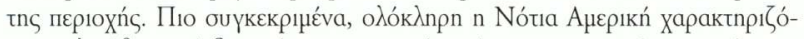

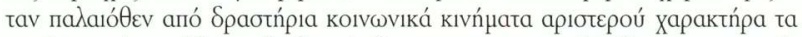

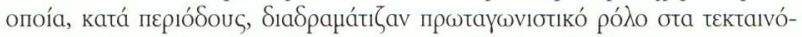

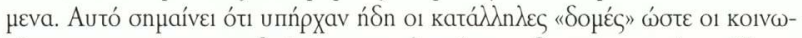

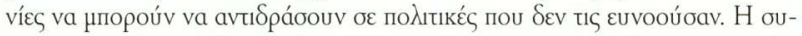

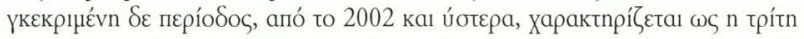

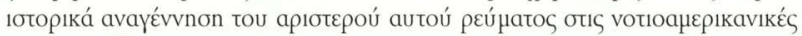
кoIvavię. ${ }^{35}$

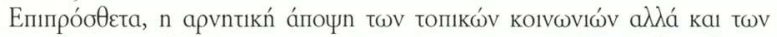

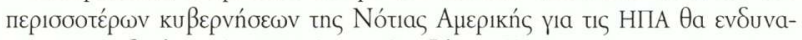

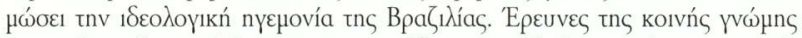

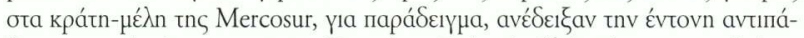

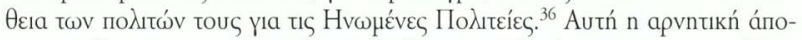

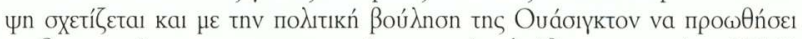

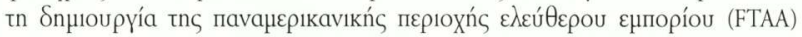

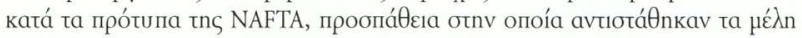

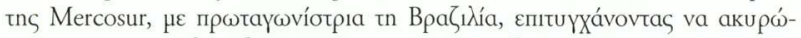

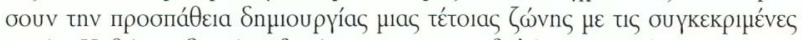

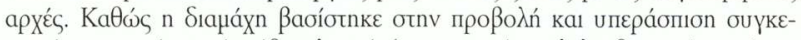

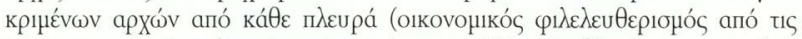

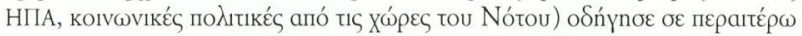

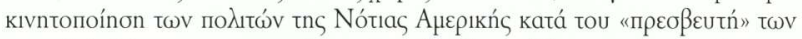
vยо

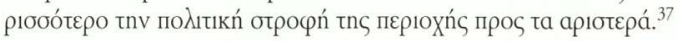

34. K. Bolduc, "Venezuela's First Meeting as Mercosur Member Begins Today», Council of Hemispheric Affairs, 20 louגiou 2006.

35. E. Sader, «Taking Lula’s Measure», New Left Review, tx. 33, 2005, о. 60.

36. J. Anchieta Neves - L. Stocco - S. Da Silva, «Is Mercosur an optimum currency area?», MPRA Paper No. 2758, 2007, o. 4.

37. N. Yeates - B. Deacon, "Globalism, Regionalism and Social Policy: framing the debate», UNU-CRIS Occasional Papers, 0-2006/6, o. 4. 


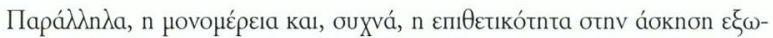

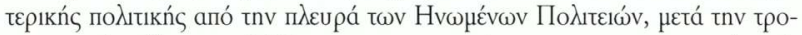

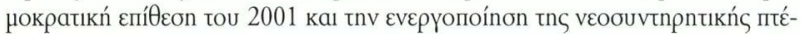

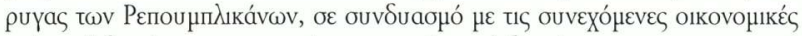

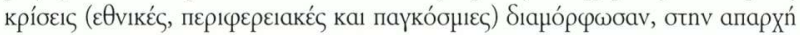

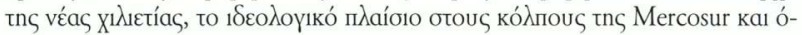
$\mathrm{X}^{1}$ Hóvo.

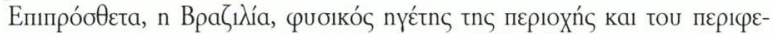

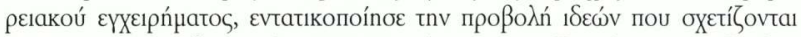
$\mu \varepsilon$ tnv kolv

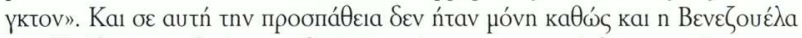

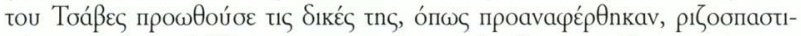

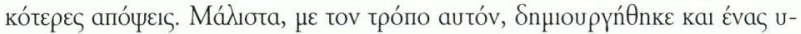

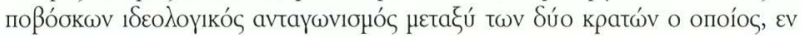

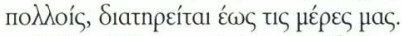

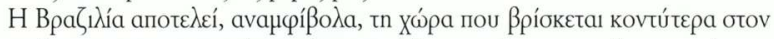

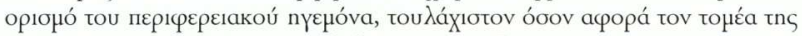

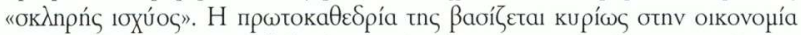

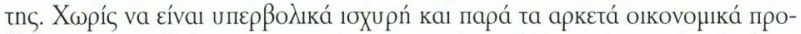

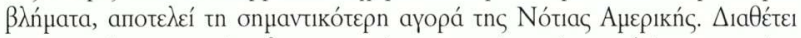

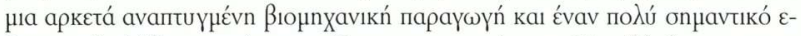

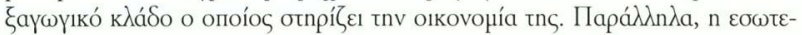

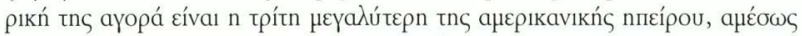

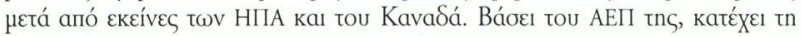

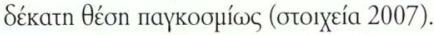

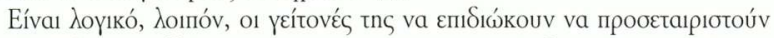

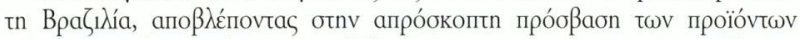

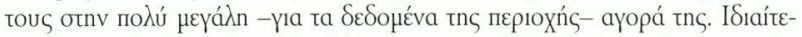

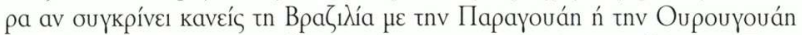

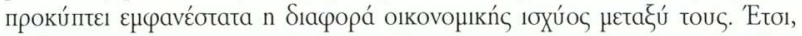

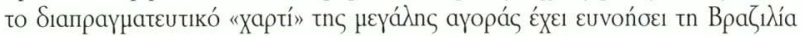

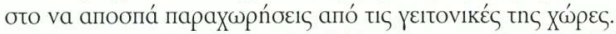

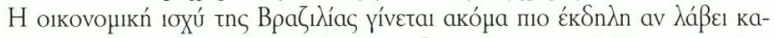

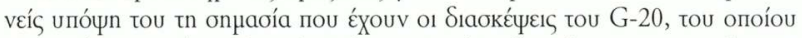

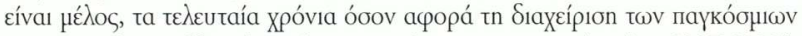

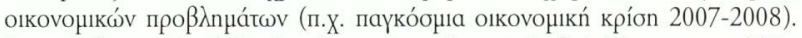

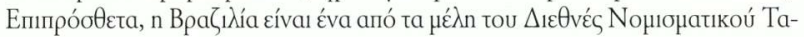




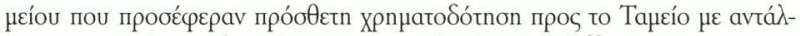

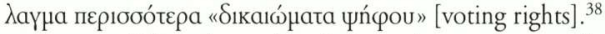

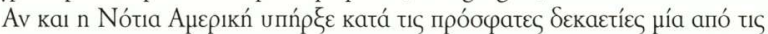

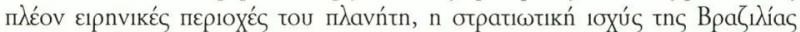

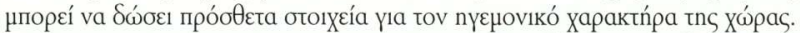

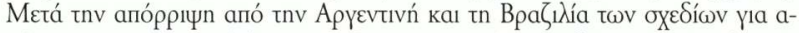

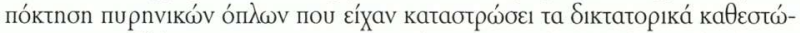

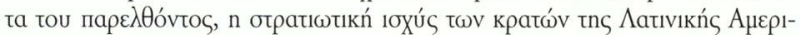

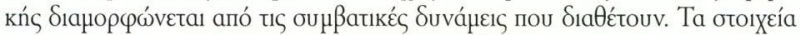

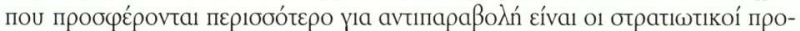

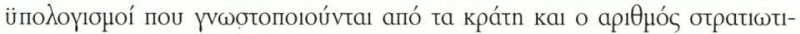

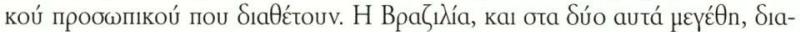

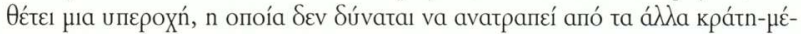

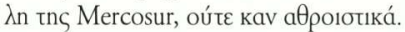

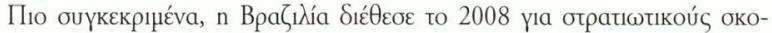

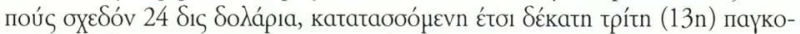

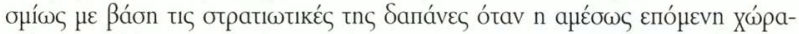

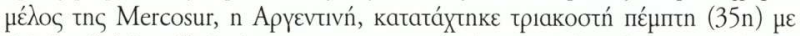

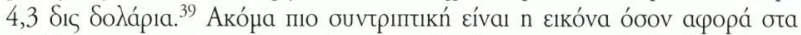

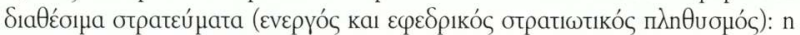

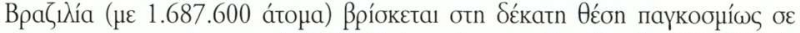

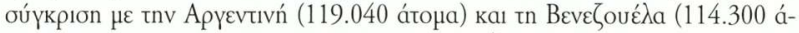

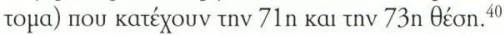

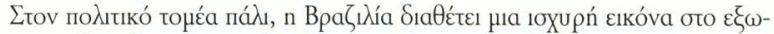

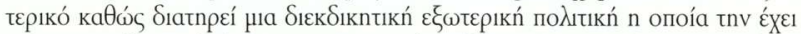

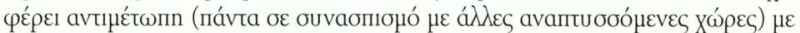

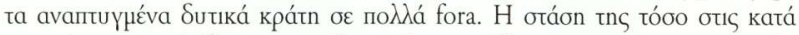

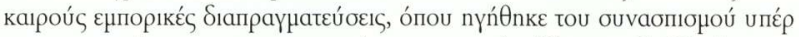

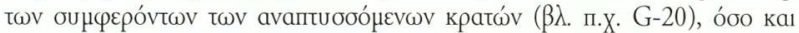

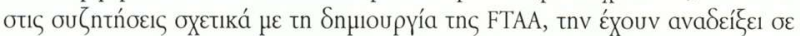

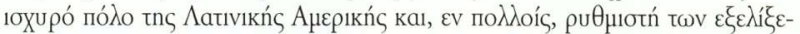

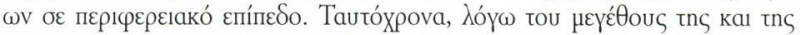

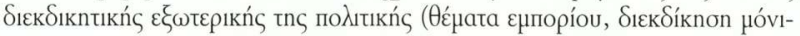

38. IMF Press Release No. 10/418, 5 Nozußpíou 2010, www.imf.org/external/np/sec/pr/ 2010/pr10418.htm.

39. CIA Factbook 2007.

40. Center for Strategic and International Studies, 2006. 
uns Ө

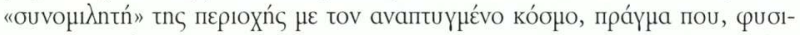

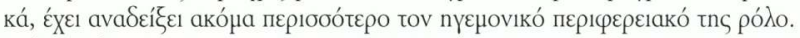

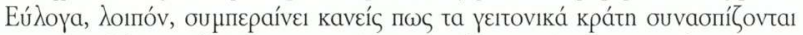

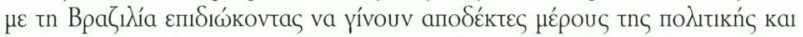

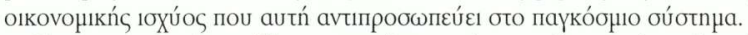

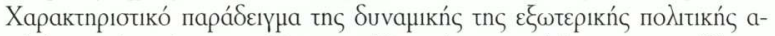

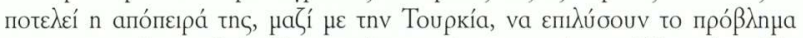

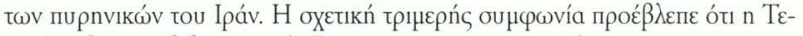

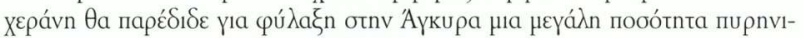

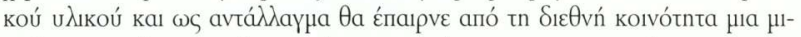

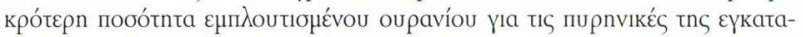

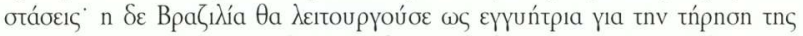

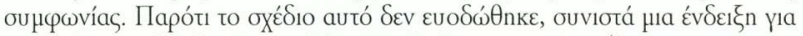

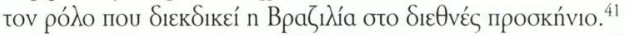

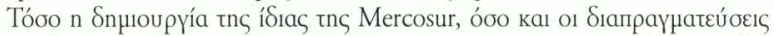

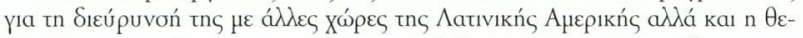

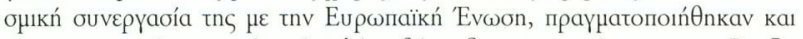

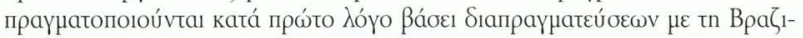

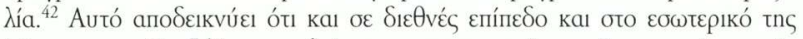

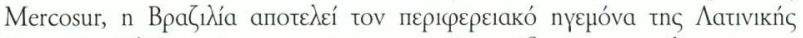

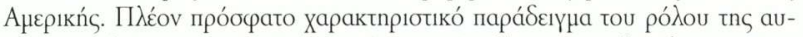

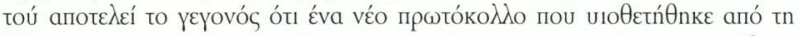

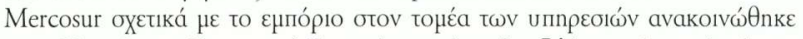

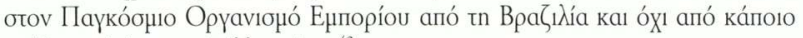

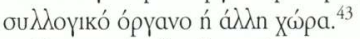

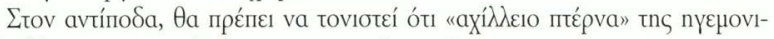

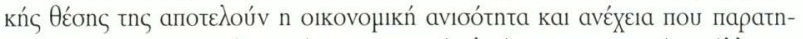

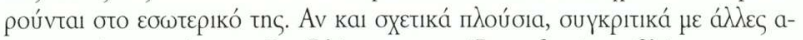

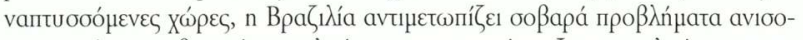

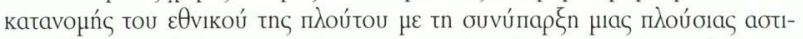

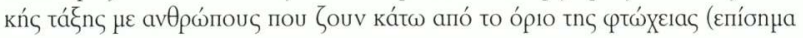

41. The Guardian, «The text of the Iran-Brazil-Turkey deal», http://www.guardian.co.uk/ world/julian-borger-global-security-blog/2010/may/17/iran-brazil-turkey-nuclear.

42. S. Burges, "Withour Sticks or Carrots: Brazilian Leadership in Sourh America During the Cardoso Era, 1992-2003", ó.п., о. 33.

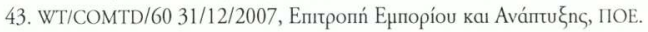




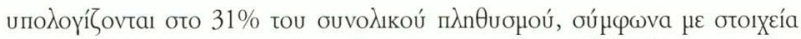

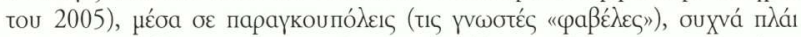

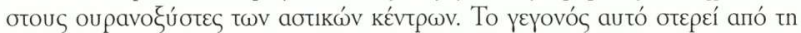

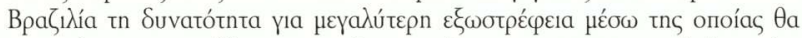

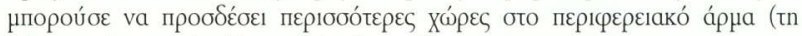

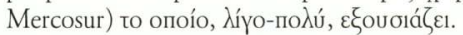

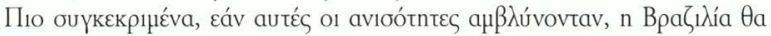

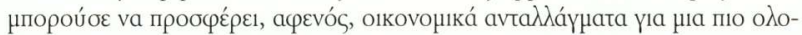

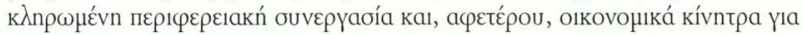

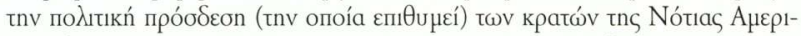

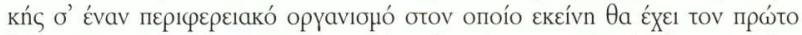

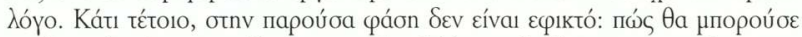

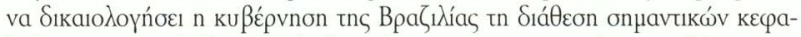

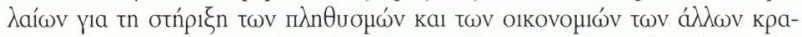

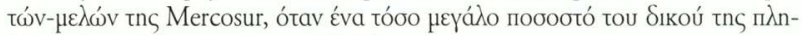

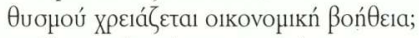

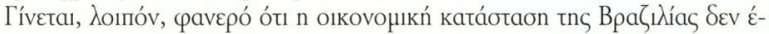

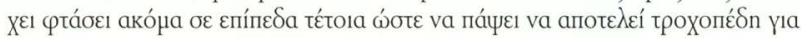

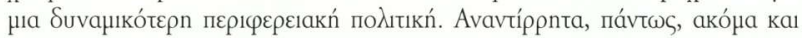

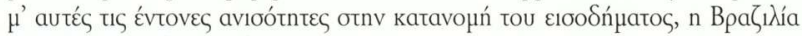

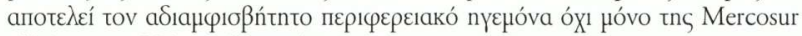

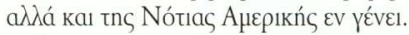

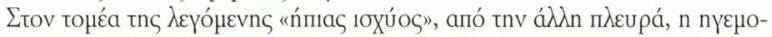

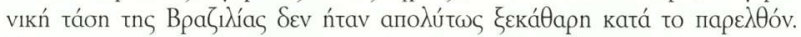

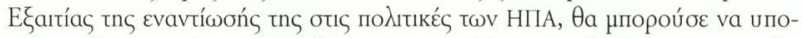

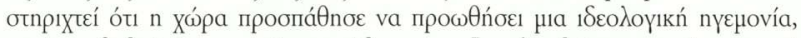

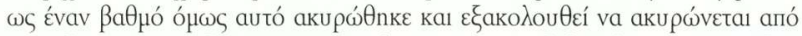

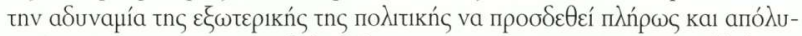

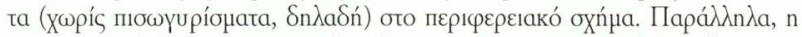

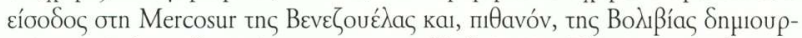

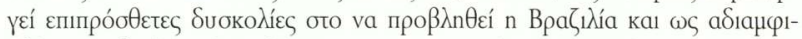

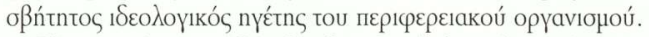

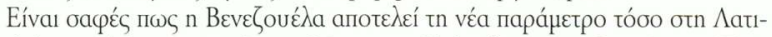

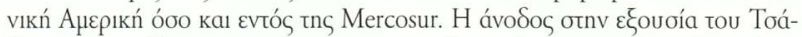

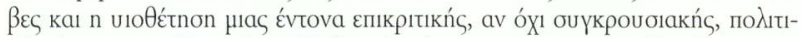

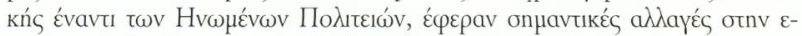

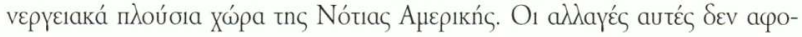




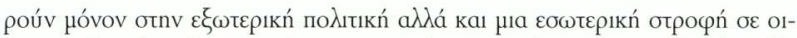

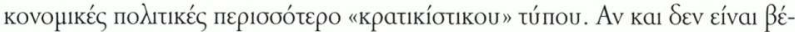

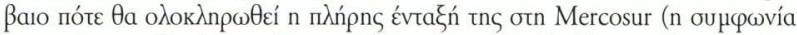

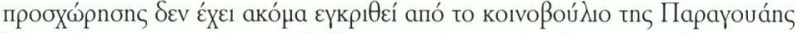

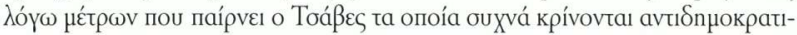

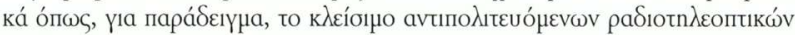

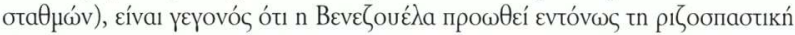

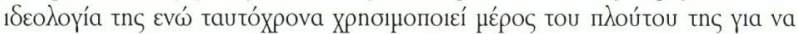

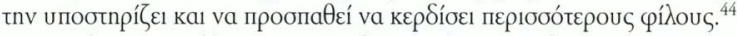

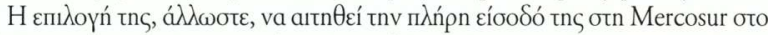

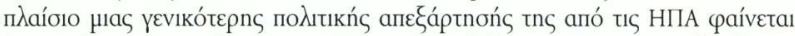

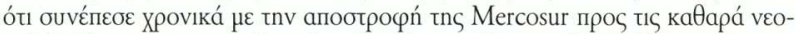

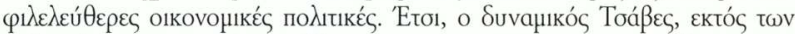

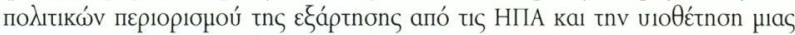

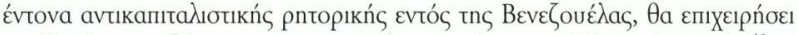

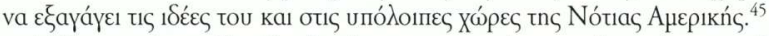

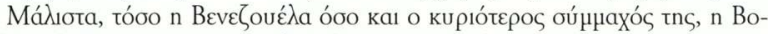

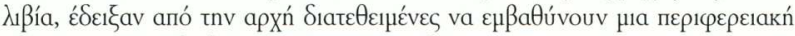

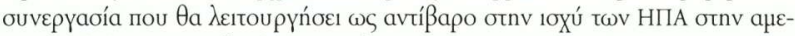

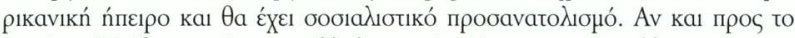

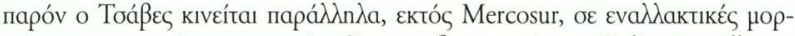

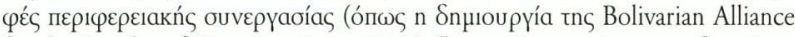

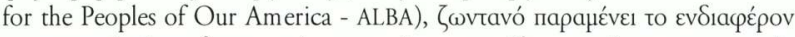

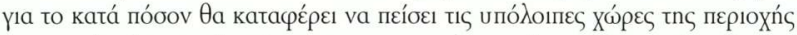

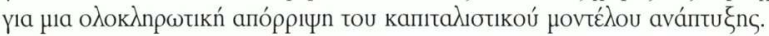

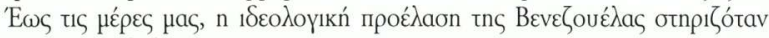

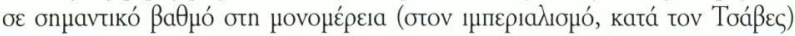

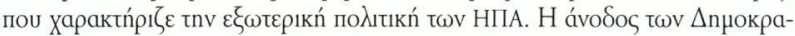

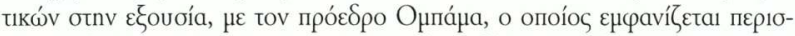

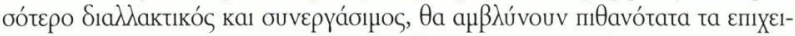

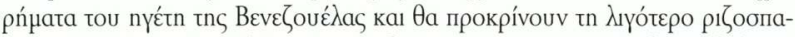

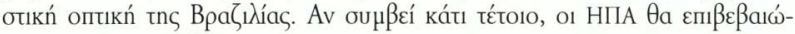

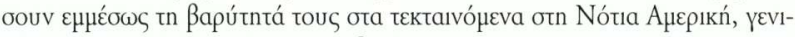

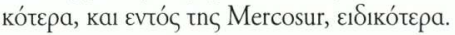

44. http://www.coha.org/category/in-the-news.

45. http://www.venezuelanalysis.com/news.php?newsno=1843. 


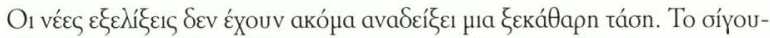

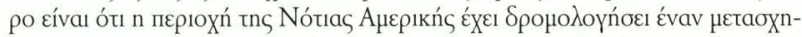

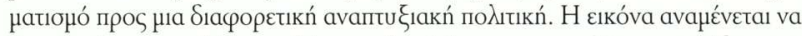

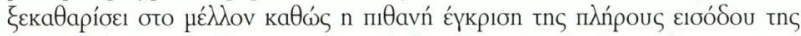

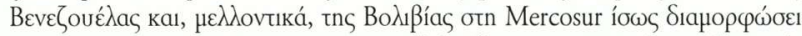

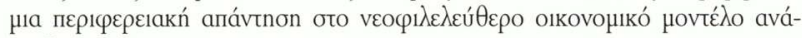
пाuदूns.

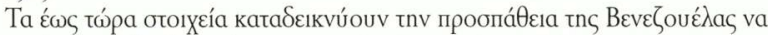

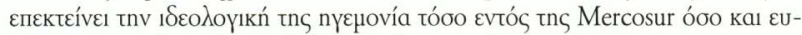

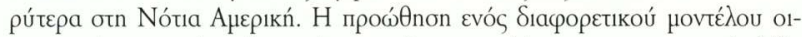

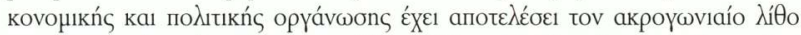

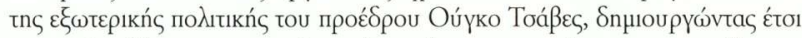

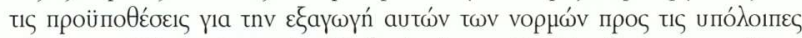

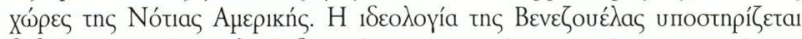

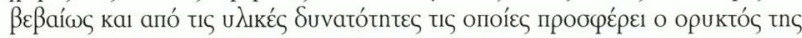

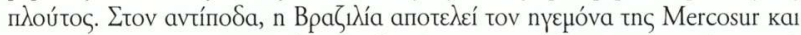

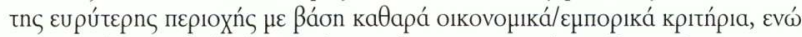

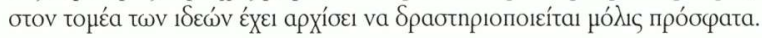

\section{5. ¿YMПЕРАЕMATA}

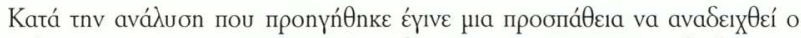

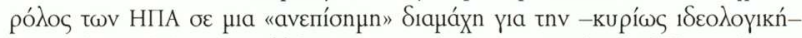

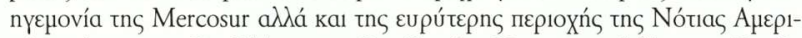

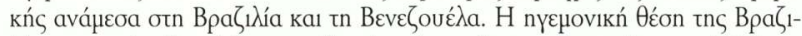

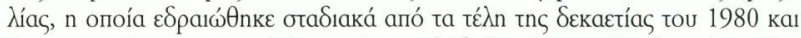

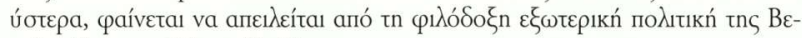

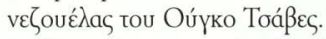

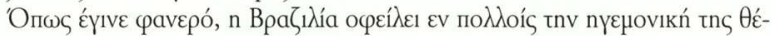

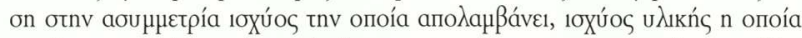

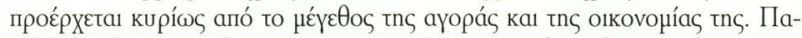

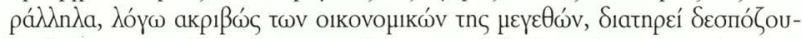

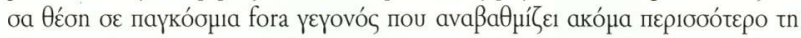

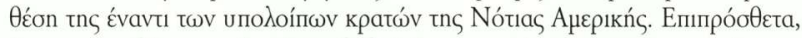

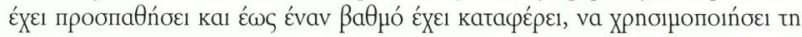

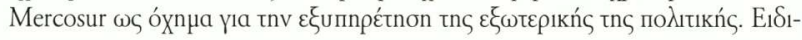




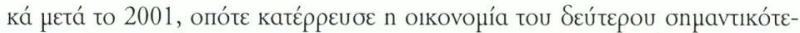

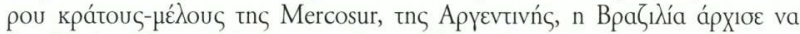

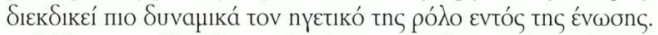

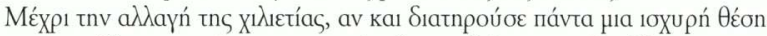

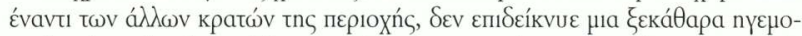

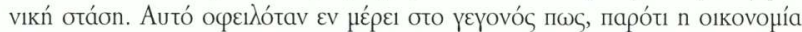

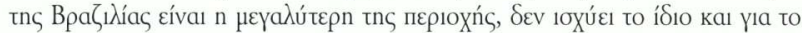

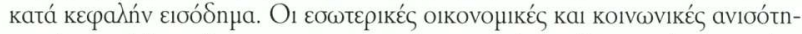

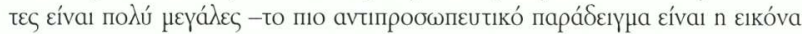

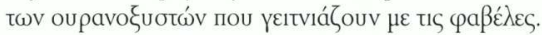

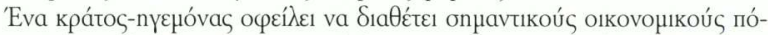

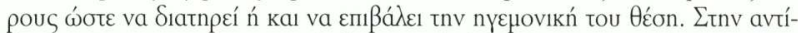

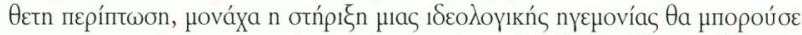

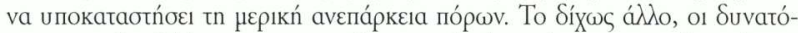

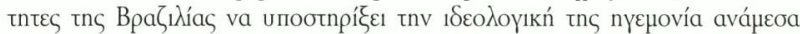

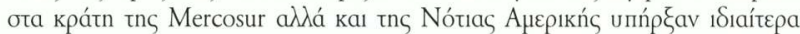

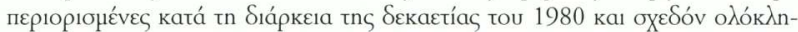

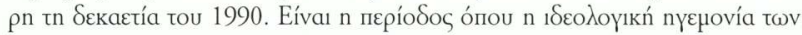

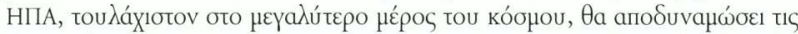

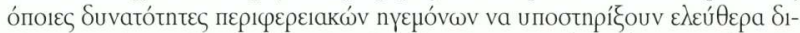

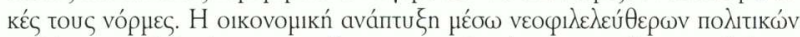

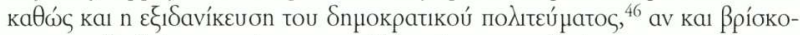

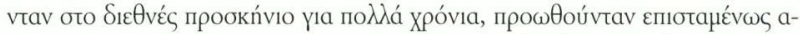

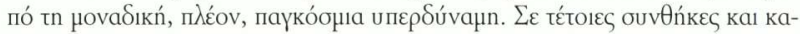

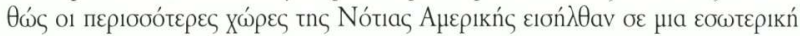

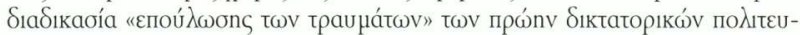

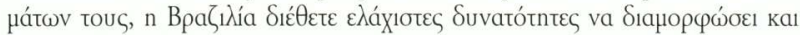

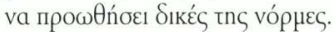

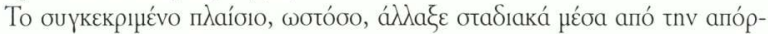

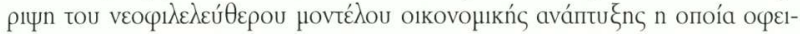

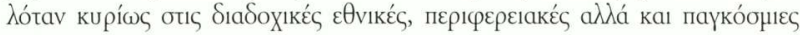

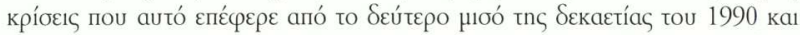

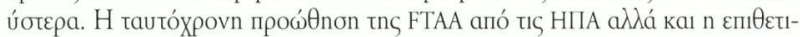

46. Y. Shi, "The Evolution of International Norms in Modern and Contemporary Civilization", Global Review, xx. 2, 2006, o. 20` St. Finkel - A. Pérez-Liñán -M.A. Seligson, «The Effects of U.S. Foreign Assistance on Democracy Building, 1990-2003», World Politics, то́н. 59, Апрі́̀̀ıs 2007, о. 407. 


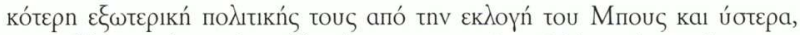

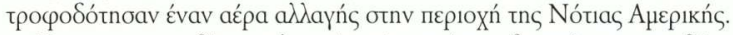

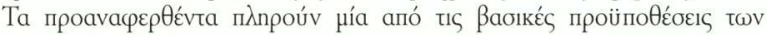

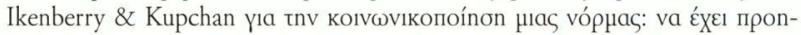

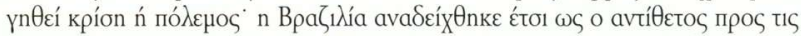

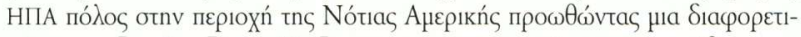

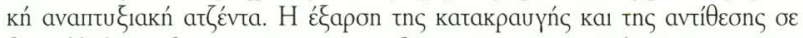

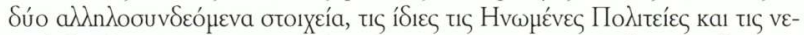

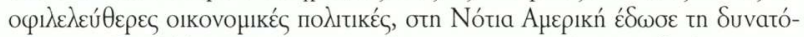

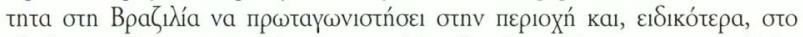

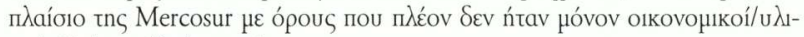

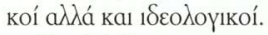

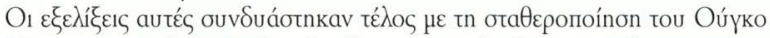

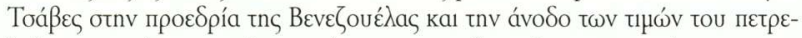

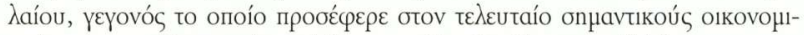

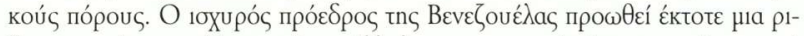

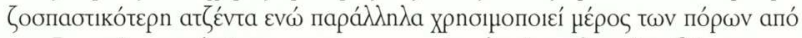

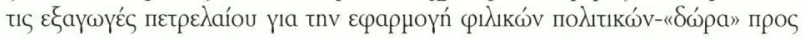

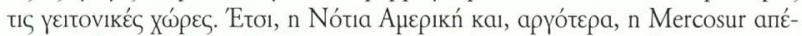

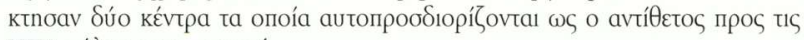

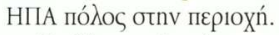

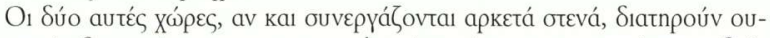

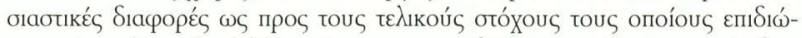

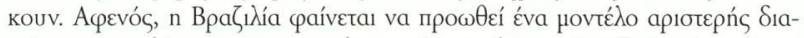

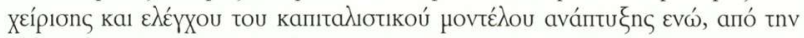

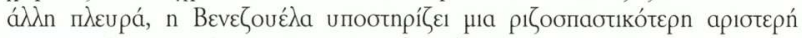

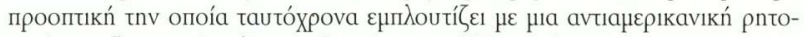

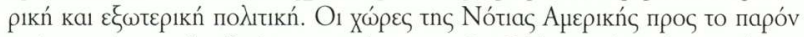

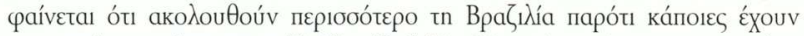

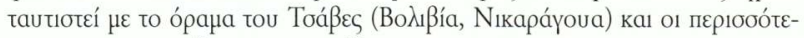

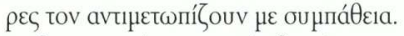

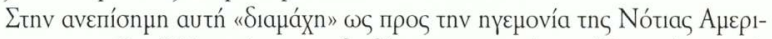

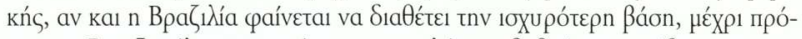

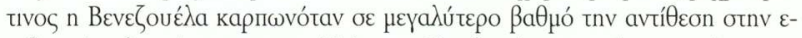

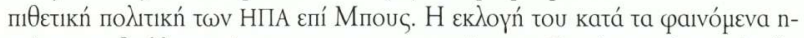

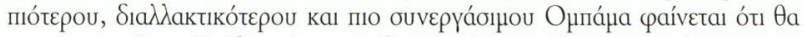

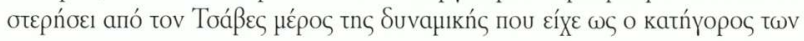




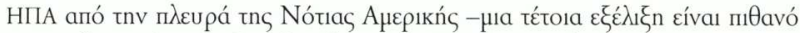

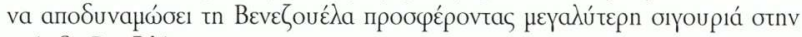

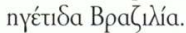

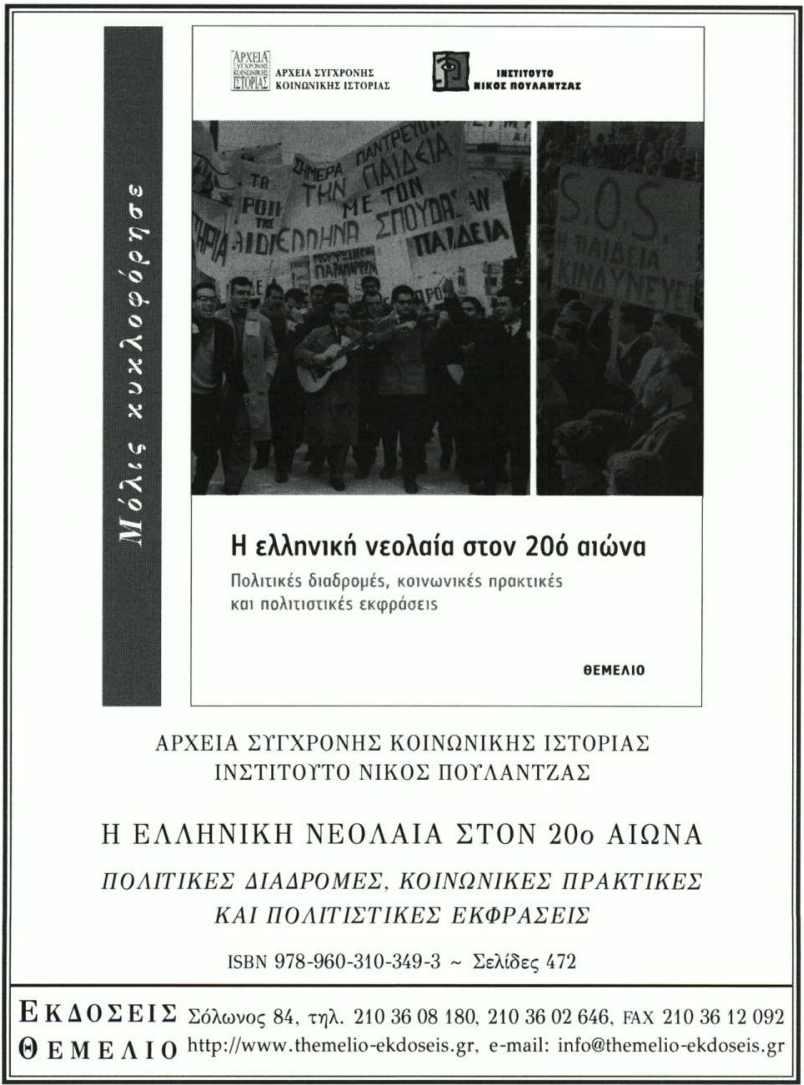

